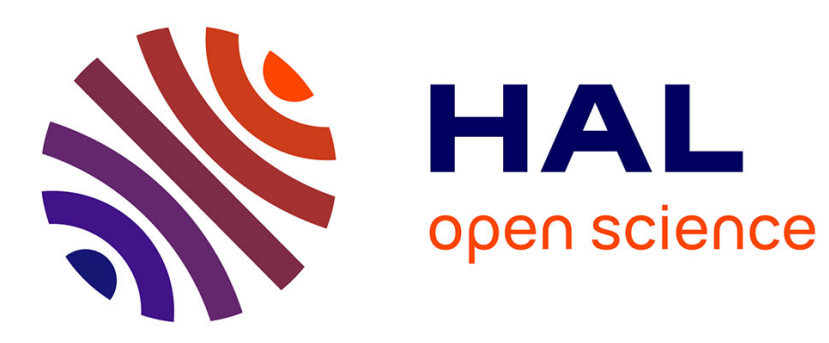

\title{
Circulation in the Mediterranean Sea
}

Claude Millot, Isabelle Taupier-Letage

\section{To cite this version:}

Claude Millot, Isabelle Taupier-Letage. Circulation in the Mediterranean Sea: Updated description and schemas of the circulation of the water masses in the whole Mediterranean Sea.. A. Saliot. The Mediterranean Sea, The Mediterranean Sea (5-K), Springer, pp.29-66, 2005, Handbook of Environmental Chemistry, $9783540314929 \bullet 9783540250180$. 10.1007/b107143 . hal-01191856

\section{HAL Id: hal-01191856 https://hal.science/hal-01191856}

Submitted on 7 Sep 2015

HAL is a multi-disciplinary open access archive for the deposit and dissemination of scientific research documents, whether they are published or not. The documents may come from teaching and research institutions in France or abroad, or from public or private research centers.
L'archive ouverte pluridisciplinaire HAL, est destinée au dépôt et à la diffusion de documents scientifiques de niveau recherche, publiés ou non, émanant des établissements d'enseignement et de recherche français ou étrangers, des laboratoires publics ou privés. 


\title{
CIRCULATION IN THE MEDITERRANEAN SEA
}

\author{
ClAude MILLOT AND ISABELLE TAUPIER-LETAGE
}

Antenne du Laboratoire d'Océanographie et de Biogéochimie

Université de la Méditerranée et Centre National de la Recherche Scientifique (UMR 6535)

BP 330, F-83505 La Seyne/mer

\section{isabelle.taupier-letage@univ-amu.fr}

Hdb Env Chem Vol. 5, Part K (2005): 29-66 DOI 10.1007/b107143

\section{Contents}

1. Introduction

1.1. The overall functioning

1.2. The problems about the circulation

2. The data sets

2.1. The remotely sensed data sets

2.2. The in situ data sets

3. The circulation of the surface water

3.1. AW in the western basin

3.2. AW in the eastern basin

4. The circulation of the intermediate and deep waters

4.1. LIW

4.2. AeDW, AdDW, TDW and WMDW

5. Discussion

5.1. The dynamical phenomena

5.2. Some implications for environmental chemistry

6. Conclusion

\section{Abstract}

The overall functioning of the Mediterranean Sea, which transforms Atlantic Water (AW) into Mediterranean Waters (MWs), has been comprehended for a while, and the process of dense water formation, which leads AW to sink offshore in specific northern zones of the western and the eastern basins, has been studied in the world ocean. However, the circulation of the various waters from/to the basins openings to/from the zones of sinking is still debated in the western basin, while a similar debate is only being initiated in the eastern one. The differences between the circulation schemas published up to now can be large and they have already been commented in papers recently published. To provide a coherent introductory chapter, only the authors' analysis is presented hereafter.

Overall, and due to the Coriolis effect, all waters (AW and MWs) that circulate at basin scale tend to follow, in the counterclockwise sense, the isobaths at their own level. Hence they tend to describe, in both the western and the eastern basins, quasi 
permanent gyres a few 10s km thick and a few 1000s km long along the continental slope. This simple schema is complicated by the fact that the southern parts of both gyres described by AW are markedly unstable, the AW inflow being hence identified with the so-called Algerian Current and Libyo-Egyptian Current and generating specific systems over the whole depth. Indeed, these currents (100-200 m deep) meander and generate, a few times per year, anticyclonic eddies that can reach diameters of 100-200 $\mathrm{km}$ (and even more), propagate downstream (i.e. eastward) at speeds up to a few $\mathrm{km} /$ day, and sometimes extend down to the bottom $(2-3000 \mathrm{~m})$. Hence, these eddies follow the deeper isobaths, separate from their parent current where these isobaths diverge from the upper continental slope, and drift for years (up to 3 at least) in the central part of the basins, possibly coming back shoreward where they interact with their parent current, sometimes in a dramatic way. These eddies entrain AW and MWs from the peripheral part of the basins towards their central part, together with eddies induced by the wind in the eastern basin only and having similar characteristics. In both basins, the northern parts of the gyres display specific features linking them to the zones of AW sinking, hence being identified (more easily in the western basin than in the eastern one due to the topography) with the so-called Northern Currents. In addition to these circulation features, and because the various openings are only a few $100 \mathrm{~s} \mathrm{~m}$ deep, the deeper MWs must be uplifted before outflowing. This is achieved permanently and more or less everywhere through continuous mixing with less dense waters and uplifting by newly formed denser waters. This is also achieved when and where intense mixing with other waters (cascading from sills or sinking) and sucking upward straits occur.

Keywords: Mediterranean Sea, western and eastern basins, water masses, general circulation, mesoscale

Abbreviations

ADCP: Acoustic Doppler Current Profiler

AW: Atlantic Water

AdDW: Adriatic Deep Water

AeDW: Aegean Deep Water

AVHRR: Advanced Very High Resolution Radiometer

CTD: Conductivity (to compute Salinity) Temperature Depth (actually Pressure) probe

LIW: Levantine Intermediate Water

MWs: Mediterranean Waters

NOAA: National Oceanic and Atmospheric Administration

POEM: Physical Oceanography of the Eastern Mediterranean

SST: Sea Surface Temperature

TDW: Tyrrhenian Dense water

WMDW: Western Mediterranean Deep Water

XBT: EXpendable BathyThermograph probe

XCTD: EXpendable Conductivity Temperature Depth probe 


\section{Circulation in the Mediterranean}

\section{Introduction}

\subsection{The overall functioning}

The semi-enclosed Mediterranean Sea is characterised by evaporation exceeding precipitation and river runoff (the specific case of the Black Sea will be addressed later). [1], supported by [2], considered that this was a characteristic not only of both the western and the eastern basins ${ }^{1}$, but also of the Japan Sea, and proposed a preliminary analysis of the differences and -generally not agreed yet- similarities between these three «medi-terranean» seas. Hence, any reference to rotation specified hereafter is for the northern hemisphere.

Would the Strait of Gibraltar be closed, the level of the sea would decrease by 0.5-1 m.year-1. The tendency for a difference in level between the sea and the Atlantic Ocean leads the Atlantic Water (AW, http://ciesm.org/events/RT5-WaterMassAcronyms.pdf) encountered at the surface right west of Gibraltar to flow into the sea at a rate of $\sim 1$ Sverdrup $\left(1 \mathrm{~Sv}=10^{6} \mathrm{~m}^{3} \mathrm{~s}^{-1}\right)$. With respect to the geoïd, that is the surface of a theoretical fluid at rest modified only by gravity, the level of the easternmost part of the sea is few metres below that of the ocean. For the time being, inaccuracies in quantifying the various parameters and natural variability do not allow a more precise estimation of these quantities.

Typical values for AW at Gibraltar are $\mathrm{T} \sim 15-16{ }^{\circ} \mathrm{C}, \mathrm{S} \sim 36-37$ and $\sigma \sim 26-27$ (densities of 1.026-1.027). While progressing within the sea, the incoming AW is continuously modified, firstly due to interactions with the atmosphere, but also due to mixing with older AW remained at the surface and with the waters underneath. All along its course, AW is seasonally warmed (up to $20-28{ }^{\circ} \mathrm{C}$ in the mixed layer) or cooled (down to $\sim 13^{\circ} \mathrm{C}$, or locally less) but, overall, its salt content increases (up to 38-39) and it is thus made denser (up to 28-29). In fall, in the northern parts of both basins, AW is markedly modified but it remains at the surface. In winter, cold and dry air masses entrained by relatively brief episodes of strong northerly winds induce marked evaporation (increase of salinity and loss of latent heat) and direct cooling (loss of sensible heat) of AW, resulting in a dramatic increase of its density (above 29) that

\footnotetext{
${ }^{1}$ The term "basin" is assigned exclusively to the two major parts of the Mediterranean Sea
} 
makes it sink. Sinking occurs in a series of specific zones, generally located in the northern parts of the basins, according to two different processes.

A secondary process occurs on the shelves. It results from the fact that waters there are markedly cooled because the reduced depth does not represent a large reservoir of heat, i.e. of buoyancy, i.e. the shallower the depth the cooler the temperature can become and the higher the density can become too. However, shelf waters are relatively fresh in general (due to river runoff) so that they cannot get a density allowing them to sink down to more than $\sim 1000 \mathrm{~m}$. Although such waters are identified wherever adequate conditions are encountered, they represent relatively low amounts and, generally, they are rapidly lost due to mixing induced by the relatively intense circulation alongslope. Hence, we consider that their circulation is not markedly different from that of AW.

The major process (regarding the volumes involved) occurs offshore in some subbasins $^{2}$. Fundamentally, densified AW sinks and mixes with the denser waters underneath, so that the mixture continuing to be densified will reach relatively high densities. Details about this process that forms the largest amounts of dense waters are given hereafter, especially in section 5. Now, depending on the subbasin, the mixture will have specific characteristics, leading to a set of more or less dense Mediterranean Waters (MWs) that will be thus qualified either as intermediate or deep. The Levantine Intermediate Water (LIW, see section 4.1) is the warmest and saltiest intermediate water, and the MW produced with the largest volume. Because of its characteristics and amount, LIW is recognised more or less everywhere in the sea. Due to its relatively low density, it is found just below AW and hence it mixes with AW as soon as AW starts sinking. If the mixture of AW and LIW, evaporated and cooled more and more, reaches densities larger than $\sigma \sim 29$, it can sink down to the bottom and form the deep waters (see section 4.2). The overall formation rate of intermediate and deep MWs is estimated to be $\sim 90 \%$ of the AW inflow at Gibraltar (10\% being evaporated), among which $\sim 3 / 4$

2 We assign the term "subbasin" to all parts of the western and eastern basins of the Mediterranean Sea that are usually referred to as seas, basins or passages. For instance, the parts of the eastern basin commonly named Ionian Sea, Cretan Passage or Levantine Basin, being not basically different, will all be qualified as "subbasins". We omit the term subbasin when self-explanatory. 
(resp. 1/4) are formed in the eastern (resp. western) basin. These values lead to an average residence time of 50-100 years ${ }^{3}$.

\subsection{The problems about the circulation}

These intermediate and deep MWs then circulate and can still be identified more or less far from their zone of origin. They continuously mix and, finally, outflow at Gibraltar as a rather homogeneous water ("the" Mediterranean Water), which is colder (13.0-13.5 ${ }^{\circ} \mathrm{C}$ ), saltier (38.0-38.5) and denser (28.0-28.5) than AW there. Therefore, the Mediterranean Sea is a machine that transforms AW present at the surface right west of the Strait of Gibraltar into denser water that is recognised at 1000-1200 m in most of the northern Atlantic Ocean.

Apart from this well-agreed overall functioning, the circulation of the various waters from/to Gibraltar to/from the zones of sinking is still debated nowadays. There are several reasons for that. First, oversimplified schemas, and even surface current "maps" (i.e. schemas with wind effects and/or seasonal variability quantified, although based on data sets markedly insufficient), have been published relatively early and trusted. Second, different forcings can induce roughly similar circulation patterns, hence making difficult any discrimination and the understanding of the actual processes. In a semienclosed basin for instance, winds blowing seawards, evaporation and dense water formation all induce a counterclockwise circulation of the surface water. Third, although a large amount of satellite information is available in the visible and infrared bands since about three decades, it has generally been regarded as unreliable and representative of the very superficial layer only; hence, it has not been widely used. Fourth, the oceanic/marine domain is effectively much more variable (at mesoscale, some 10s to a few 100s $\mathrm{km}$ ) than initially expected, it is hostile for human activity (surface agitation, lack of visibility, pressure, corrosion, etc.) and in situ work is relatively expensive. Last but not least, although field oceanographers need modellers to solve equations and check the hypotheses they put forward from the analysis of their data sets, most of the

\footnotetext{
${ }^{3}$ As previously said and for the time being, inaccuracies in quantifying the various parameters and natural variability do not allow a more precise estimation of these quantities.
} 
modellers rely more on their simulations (encompassing up to several annual/decadal cycles!) than on the analysis of "such a low amount of in situ data"!

However, the debate about the major features of the circulation in the western basin might about to become a debate of the past while, for the eastern basin, it is just being initiated. Indeed, intensive experiments involving numerous and sophisticated instrumentation, as well as theoretical and numerical studies, have been conducted in the western basin since several decades because major labs were from the (northern) riparian countries: overall features there were thus better described and known. Moreover, some of the key-hypotheses that had remained controversial for about two decades have recently been fully validated by dedicated in situ measurements [3]. In the eastern basin, intensive operations have only been initiated less than two decades ago, mainly in the northern and central parts of the basin. In addition, most of these operations were parts of the POEM programme, whose leaders have proposed a circulation schema (e.g. [4, 5]) that ignores the previous ones (especially [6]) and completely obliterates the southern part of the basin. Indeed, [6] argues for an alongslope counterclockwise circulation due to the Coriolis effect around the whole basin, while the POEM schema claims for major currents meandering across most of its central part. Recently, both our data analysis [7] and numerical works done by other teams (e.g. [8]) converged to support the analysis we made about 10 years ago $[1,2]$. Our analysis is consistent with the one by [6], mainly adding information about the mesoscale features, and is thus dramatically different from -if not opposed to- the POEM one!

It is therefore impossible to present a view of the circulation synthesised from all the published papers, would it have been the aim of such a handbook volume and introductory chapter. Furthermore such a review has been recently done for both the western basin [9] and the eastern one [7]. To provide the reader with a coherent analysis (even though there is no consensus yet), the presentation hereafter is thus restricted to the authors' analysis. Only the most recent or major references are indicated, the reader being asked to refer to [9, easily accessible via Internet] and [7, accessible via http://lobtln.chez.tiscali.fr/] for a more detailed and documented presentation of the phenomena. The remotely sensed and in situ data sets used for this 
analysis are described in section 2. The circulation of AW is presented in section 3 and that of MWs in section 4. Specific aspects of the circulation and consequences for chemistry (and biology as well) are envisaged in a discussion section (5) and a conclusion is drawn in section 6 .

\section{The data sets}

Although the most recent numerical simulations now support the schematic circulation schemas that are proposed hereafter, these schemas are mainly based on the analysis of all the available data sets that, therefore, need to be briefly discussed first.

\subsection{The remotely sensed data sets}

Several physical parameters can be measured from space. The first one (in terms of precedence, space and time intervals adequacy, availability and processing easiness, usefulness) is the sea surface temperature (SST), since any body emits in the thermal infrared, mainly at a specific wavelength that is related to the temperature of that body. Images are also provided in the visible during daytime, the back-scattered signal (colour) being integrated over a layer up to a few $10 \mathrm{~s}$ m thick in a way that depends on the water transparency. The sea surface height is measured along the satellite track with a nadir-directed radar. The sea surface salinity starts being estimated (although too roughly for circulation purposes yet) from the emission at a specific frequency. As done worldwide (although not by all teams working on the Mediterranean Sea!), our team has made an extensive use of satellite measurements in the thermal infrared for several reasons.

The major reason is that, from a dynamical point of view, geophysical fluids are mainly characterised by their density, which depends on temperature, salinity and pressure (the latter having a negligible effect at the surface). In addition, although temperature and salinity ranges vary separately in both time and space, their spatial variations have to be related, at least on average. More specifically, temperature and 
salinity fronts (and gradients that are perpendicular to them) have to be parallel ${ }^{4}$, at least locally and on average, not considering any spurious effect (see below).

Parallel temperature and salinity gradients can either have the same sense (temperature and salinity thus compete and the density gradient can not be defined a priori) or be opposed (thus clearly defining the sense of the density gradient). The incoming AW is always fresher that the resident $\mathrm{AW}$, but it is warmer (by a few ${ }^{\circ} \mathrm{C}$ ) in winter and cooler (by up to $10-15^{\circ} \mathrm{C}$ ) in summer. Therefore, SST gradients are particularly informative about density gradients in winter. In spring and fall, the SST can be locally and temporally homogeneous, hence uninformative. In summer, the temperature of the very surface layer might not be representative of that of the mixed layer (see below), which requires some know-how for its analysis. Whatever, dealing with dynamical features does not require considering absolute SST values as long as salinity values (hence density ones) remain unknown. We personally pay attention to even weak SST gradients that are significant (see below), and we infer circulation features just focusing visually on the spatial SST distribution ${ }^{5}$ at a given time (plus from time to time, obviously).

The second reason that makes infrared data valuable is their space and time sampling interval, as collected for instance from the NOAA / AVHRR radiometers. Images are collected by a scanner (pixel of about $1 \mathrm{~km} \times 1 \mathrm{~km}$ ), on both sides of the track (swath of $\sim 3000 \mathrm{~km}$ ), a few times per day at mid latitudes, and in several frequency bands (allowing computation of SST values with an accuracy of $\sim 0.1{ }^{\circ} \mathrm{C}$ ). A third reason is that, being easily processed (since about three decades), products are now made easily available by some receiving centres (e.g. http://eoweb.dlr.de).

${ }^{4}$ Indeed, one can hardly imagine a temperature front (representative of a water changing in one direction mainly) permanently crossing a salinity front (representative of the same water changing in another direction). Such crossing fronts, each schematised as an interface between two different waters at the surface for instance, would lead, on a temperature-salinity schema, to four points defining a rectangle, thus having different densities while all being at the surface (not considering what would occur at the intersection)!

${ }^{5}$ We thus usually represent SST data with a grey or colour table that is suitable (visually) to evidence the phenomena of interest; colour tables are thus advantageously different in winter and summer and, in fact, specific to each image. 
Problems due to warm spots, which develop during calm and sunny days at the very near surface, are definitely avoided by considering nighttime images only. However, as in the case of haze or dust clouds that can decrease the measured SST, these spurious effects are generally detected easily because they have "non-oceanographic" patterns. In addition, patterns due to warm spots, haze and dust are rapidly changing from one image to the other. The fact that the infrared signal is emitted by the very near surface is generally not a problem, due to the frequent occurrence of waves that form the mixed layer and its associated thermocline. Moreover, this signal often represents much more than the temperature of the mixed layer since it is now demonstrated that, for instance, an eddy 100-200 km in diameter, seen from space for years, can extend down to the bottom over several $1000 \mathrm{~s} \mathrm{~m}$. The only unavoidable problem is the occurrence of clouds that completely mask the sea surface. Building composite (daily, weekly, monthly) images reduces this problem and appears to be efficient for studying circulation features since they vary markedly in space but slowly in time.

Inferring circulation from the visual analysis of infrared images (i.e. from indications about the density gradients) obviously relies on theoretical bases. According to what is known as geostrophy (most of the current is proportional to the horizontal pressure gradient and perpendicular to it), this consists practically in assuming that (most of the) surface currents are roughly parallel to those isotherms that do not change too much in time. When isotherms are rapidly evolving, i.e. in some specific places such as at the nose of a propagating jet, the current has a significant component perpendicular to the isotherms. In any case, and as will be shown later, the visual analysis is very intuitive and efficient, since it allows the preliminary analysis of phenomena from the lab, more or less everywhere and all year long, thus helping in the definition of efficient in situ sampling strategies.

\subsection{The in situ data sets}

Most of the available physical oceanography data sets are vertical profiles of temperature and salinity now collected with ship-handled CTDs, as well as XBTs and XCTDs to a lesser extent. Although they are generally of the utmost quality (CTD sensors can be calibrated easily), they are often made with a sampling interval too large (a few 
$10 \mathrm{~s} \mathrm{~km}$ ) according to pre-defined regular grids. This has led to misleading interpolations, so that we personally position our CTD stations with a $\sim 5$-km spacing based on SST data received onboard in near real time (http://www.com.univmrs.fr/ELISA/). Another problem is that these data sets, generally available easily from all data centres, have been pooled to compute average values, which can be totally misleading about actual processes. For instance in the Algerian subbasin, LIW flows along the continental slope (especially northward along that of Sardinia) while pieces of it are occasionally pulled away and transported toward the central part of the subbasin by mesoscale features passing by. Averaging all values available in the central subbasin leads to smooth the large spatial and temporal variability of the temperature and salinity fields, hence figuring spurious gradients that suggest a permanent seaward (i.e. westward) flow of this water [3]. Autonomous CTDs that can be set on moorings allow collecting time series of the hydrological parameters, possibly on the long term to derive trends (http://ciesm.org/people/task.html).

Another large data set is provided by moored (eulerian) currentmeters that are the only mean to get locally accurate statistics about the circulation. The largest experiments now involve a few tens of currentmeters set on up to $\sim 10$ moorings for periods up to 1-2 years. Only few instruments are maintained in some specific places on isolated moorings over years up to decades. Whatever, deploying open-sea moorings requires some experience as well as a relatively large amount of equipment and fittings. In addition, moorings cannot be deployed for a long time on continental shelves due to fishing activity, and setting them on the continental slope to get measurements up to the near surface in these zones that are critical for the circulation is not easy. This is why only $\sim 200$ point $x$ year time series are available in the western basin, with $1 / 2-1 / 3$ coming from our group. Time series available in the eastern basin are $\sim 10$ times less, nearly all having been collected in the northern part. Therefore, one must consider that in situ direct measurements about the circulation are relatively few, especially in some critical zones.

Another way to collect measurements about the circulation is to use free-drifting (lagrangian) currentmeters that are now localised worldwide with the ARGOS system (embarked on the NOAA satellites). To measure surface currents, these currentmeters 


\section{Circulation in the Mediterranean}

are floating buoys that are positioned several times per day and are equipped with a drogue, to prevent them from slipping with respect to the water due to the wind drag. To measure currents at intermediate depths, these currentmeters are floats, generally ballasted to remain on some iso-density surface or equipped with active devices, which are positioned with respect to moored acoustic sources. To measure currents at greater depths, ballasted floats are programmed to periodically (about once every week) surface, remain there a few hours for being ARGOS-positioned, and then sink again to their specific depth (the distance between 2 positions being considered as the drifting distance at depth). The advantage of these lagrangian currentmeters is that they generally require reduced logistics and that they provide a very descriptive image of the circulation. However, they are not adequate to provide significant statistics about the currents in a given area.

Finally, ships of opportunity crossing the Mediterranean Sea can be, as the research ships, equipped with profiling currentmeters (such as ADCPs) and/or a set of autonomous sensors (mainly for temperature and salinity, hence forming an instrument called thermosalinometer); they can also be used to launch expendable probes (such as XBTs). Practically, they are used only from time to time during specific operations to launch XBTs, none is equipped with an ADCP yet and, hopefully, one in the western basin will be equipped this year with a thermosalinometer.

To conclude, the limited use that has been made of the remotely sensed data sets and the difficulty to collect in situ ones have prevented, up to now, from getting a consensus on the major features of the circulation. The analysis hereafter -although not fully shared yet- aims at providing a consistent analysis of the available data sets, all being considered as correct (i.e. only the interpretation of a data set can be questioned, not the data set itself), and thus at getting a correct understanding of the circulation. 


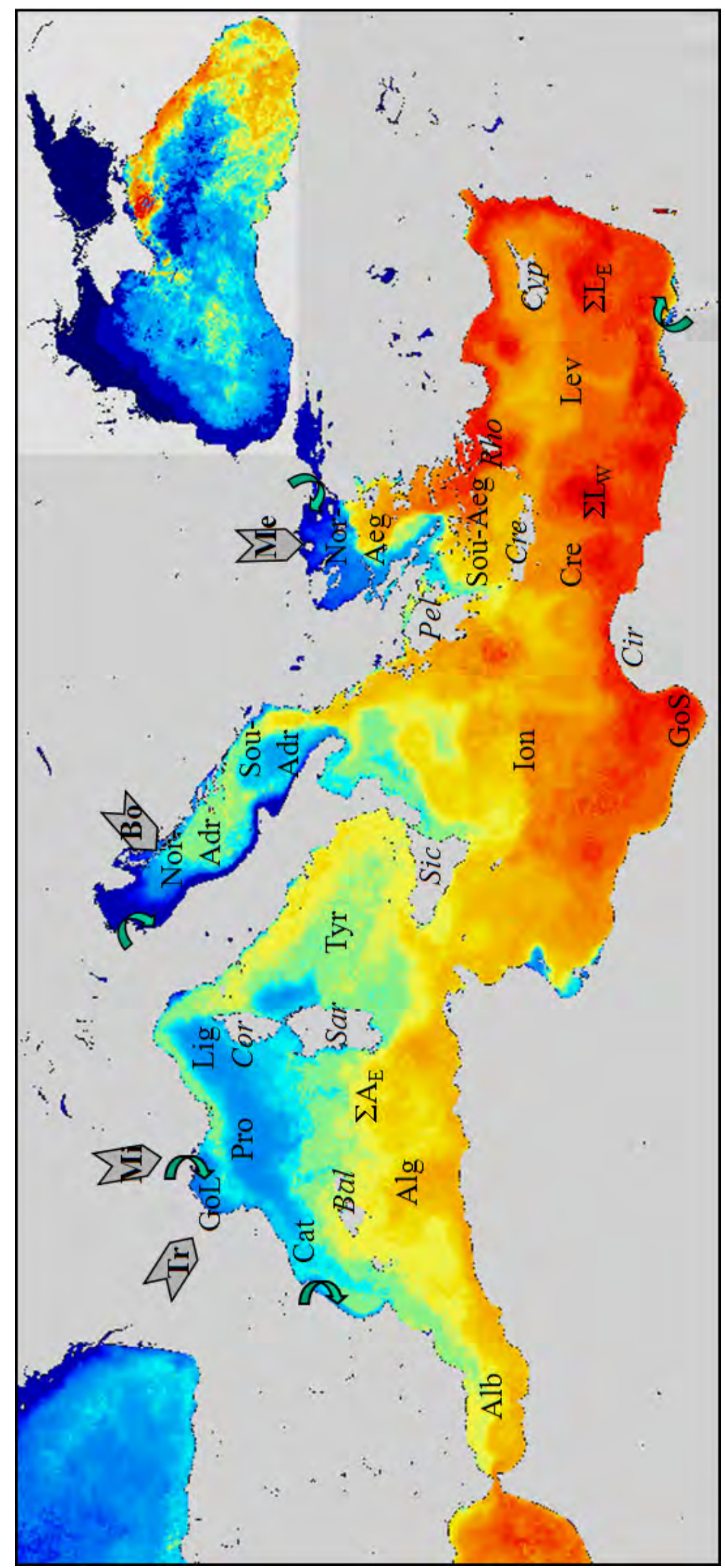

Fig. 1. SST composite image for January 1998 (the Black Sea has its own colour scale) from the DLR. See text for comments and abbreviations. 


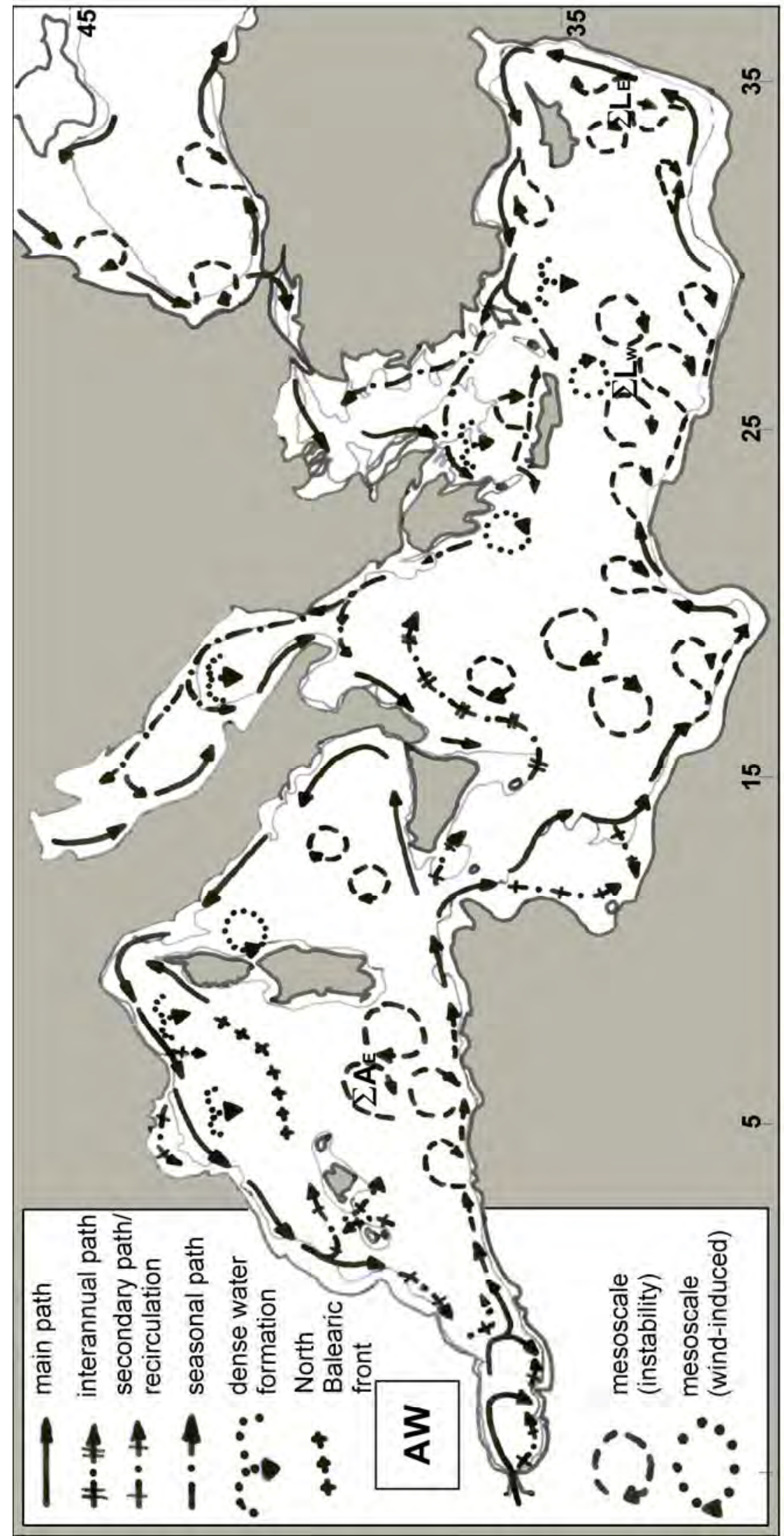

Fig. 2. Circulation of AW, inferred from [9] for the western basin and from [7] for the eastern one, and of fresh waters in the Black Sea. The thin line represents the 200-m isobath. See text for the definition of $\Sigma \mathrm{A}_{\mathrm{E},} \Sigma \mathrm{L}_{\mathrm{W}}$ and $\Sigma \mathrm{L}_{\mathrm{E}}$. 


\section{The circulation of the surface water}

The monthly composite image of January 1998 (Fig. 1) gives an overview of the SST in the Mediterranean Sea with the same colour table and without any cloud, which allows describing the general circulation of $\mathrm{AW}$ in the whole sea. This image is representative of the winter months for what concerns the SST values that range from $\sim 18^{\circ} \mathrm{C}$ (red, eastern basin) to $15-16{ }^{\circ} \mathrm{C}$ (orange-yellow near Gibraltar) to $\sim 13^{\circ} \mathrm{C}$ (light blue, dense water formation zones of the Provençal (Pro) and Ligurian (Lig) subbasins) to $\sim 10^{\circ} \mathrm{C}$ or less (dark blue, the rivers outflows (green arrows) in the Adriatic (Adr), and the Black Sea that has its own colour scale). It is also representative of all months and years for what concerns most of the general circulation features of AW (100-200 m) that do not vary seasonally in a significant way. Although this image provides indications about mesoscale features that have a large vertical extent (see below), it gives a blurred vision of those that are fast moving.

Figure 2 schematises the AW circulation features, that is surface currents, described in subsections 3.1 and 3.2. When possible, more precise terms will be used and defined in due time. For instance, the AW circulation at basin scale describes alongslope counterclockwise gyres that can bifurcate into veins or form branches. In the south of each basin, parts of these gyres are markedly unstable and are identified as the Algerian Current and as the Libyo-Egyptian Current, respectively. These currents generate mesoscale anticyclonic eddies (we clearly differentiate the terms gyres and eddies by their generation processes and dynamical features) that sometimes follow specific circuits and/or form specific systems. Note that "current" is also used for the vector that represents the speed and direction of a water particle at a given time and place.

\subsection{AW in the western basin}

It is first clear that AW west of the Strait of Gibraltar is warmer than in the Alboran (Alb), due to intense mixing within the strait. The inflow of AW, first directed northeastwards due to the orientation of the strait, then generally describes a clockwise gyre $^{6}$ (clearly seen on Fig. 1) in the west of the Alboran between Spain and Morocco. The

${ }^{6}$ Gyres are circulation features induced by wind and/or thermohaline forcing and/or topographic features (such as straits) that are clearly constrained by the bathymetry (at basin and subbasin scales). They are characterised as clockwise in the Alboran (mainly due to the orientation of the Strait of Gibraltar) and everywhere else as counterclockwise (due to the Coriolis effect). Parts of the gyres can be unstable. 
inflow usually describes a second clockwise gyre in the east of the Alboran, between Spain and Algeria, but it can also proceed more or less directly toward Algeria, or describe a third more or less organised gyre. Out of the Alboran, the AW flow restructures itself along the Algerian coast (generally near $0^{\circ}$ ), mainly due to the Coriolis effect. There, the western basin gyre starts to be clearly identified and it displays features that have justified the identification of an "Algerian Current" and of a specific associated system [10].

When the current appears as relatively stable, it is a few $10 \mathrm{~s} \mathrm{~km}$ wide and 100-200 $\mathrm{m}$ thick, and it has maximum speeds of several $10 \mathrm{~s} \mathrm{~cm} / \mathrm{s}$. However, the current is often unstable. Most of the time, it remains alongslope and generates relatively small (up to few 10s $\mathrm{km}$ in diameter, a few 100s $\mathrm{m}$ in depth) short-lived (a few weeks/months) eddies $^{7} 8$. A few times per year, however, it generates a meander growing up to 50-100 $\mathrm{km}$ in both amplitude and wavelength, hence embedding an anticyclonic eddy 50-100 $\mathrm{km}$ in diameter (of AW only). [3] have definitively demonstrated that these surface features induce an anticyclonic eddy 100-200 km in diameter in the whole deeper layer of MW (i.e. down to $\sim 3000 \mathrm{~m}$ ); since currents in this layer (several $\mathrm{cm} / \mathrm{s}$ ) can be similar over the whole depth, they might be forced by a pressure effect. The whole feature named "event" generally propagates downstream (eastwards) at a few km/day ${ }^{9}$ (it can also remain stationary for weeks/months). One can note in Fig. 1 how large are the two eddies (that are in fact events) present at that time and how efficient they are in spreading AW seawards, in this case mainly towards the Balearic Islands (Bal); after the westernmost eddy will have propagated more to the east, the Balearic Islands will no longer be concerned by recent AW. Because events are too large and deep, the spreading of the Tunisian and Sardinian shelves prevents them from continuing through the Channel ${ }^{10}$ (south) of Sardinia (Sar), so that they drift seawards, guided by the topography. They separate from their parent current, become "open-sea eddies" and

\footnotetext{
${ }^{7}$ Eddies are phenomena generated either by processes that destabilise alongslope currents (such as the Algerian Current) or by the wind stress curl locally induced by orographic effects (as described later on). They are characterised as cyclonic / anticyclonic, not constrained by the bathymetry and can move.

${ }^{8}$ Eddies are mesoscale (some $10 \mathrm{~s}$ to a few $100 \mathrm{~s} \mathrm{~km}$ ) features that will be characterised as small (up to $50 \mathrm{~km})$, medium $(50-150 \mathrm{~km})$ or large $(150-250 \mathrm{~km})$.

${ }^{9}$ Although $\mathrm{km} /$ day is a unit roughly equivalent to $\mathrm{cm} / \mathrm{s}$, it provides a more realistic quantification of propagation phenomena.

${ }^{10}$ We consider that, among the major passages, only Gibraltar is sufficiently narrow to be considered as a strait, all the others being thus considered as channels (except minor narrow passages as e.g. Bonifacio and Messina).
} 
remain trapped in the Algerian. Most of these open-sea eddies, which can have lifetimes up to $\sim 3$ years [11], follow a counterclockwise circuit along the deeper isobaths in the eastern Algerian [12]. By analogy with the notations proposed by [7] (see section 3.2), this zone where eddies tend to be trapped and markedly interact can be named $\Sigma A_{E}$ (accumulation area of eddies in the eastern Algerian). Some eddies can propagate more or less directly in the western Algerian $[11,13]$. Others can reach diameters larger than $\sim 250 \mathrm{~km}$ so that only 2 of them fill the Algerian, leading the whole Algerian Current to spread seawards upstream for months [14]. Hence, mesoscale features induced by the Algerian Current form an actual "system" and are often complex. To easily deal with these features, the largest ones (events and open-sea eddies) are called Algerian Eddies (AEs) and numbered according to the year and order of apparition (the AEs seen in Fig.1, i.e. in January 98, are 96-1 and 97-1). The markedly unstable character of the flow of AW along most of the southern coasts, and the trapping of the induced mesoscale features by the deep topography is a characteristic of all the medi-terranean seas $[1$, see section 3.2].

AW dispersed and amassed in the Algerian in such ways will spread towards the Provençal and the Catalan, forming the North-Balearic front in-between. In summer, the Catalan is relatively protected from the northwesterlies: it comes to be the warmest subbasin of the western basin while a small anticyclonic eddy is often induced in its northern part by the Pyrenees. Yearlong, AW is flowing along the western coast of Corsica (Cor), hence forming the west-Corsica vein ${ }^{11}$ of AW (that is relatively unstable too [15]).

Part of the AW flow that has progressed through the Channel of Sardinia in its southern part (the north-Tunisia vein) continues alongslope, i.e. through the Channel of Sicily into the eastern basin, hence feeding the eastern basin gyre. Another part (the Tyrrhenian vein) continues flowing counterclockwise around the Tyrrhenian (Tyr) along Sicily and the Italian peninsula before entering the Channel of Corsica. Then, it joins the west-Corsica vein so that the flow of AW reorganises itself again as the western basin gyre. This gyre continues alongslope in the Ligurian, the Provençal and the

${ }^{11}$ The term "vein" is used to figure a bifurcation of the gyre that follows then a specific route and/or encounters a specific process, and can eventually join other veins downstream. 
Catalan, up to the Algerian and the entrance of the Alboran where it closes. Several aspects of this gyre deserve to be commented:

- Although the wintertime dense water formation process drives the functioning of the sea, the basin-wide gyre of AW that is subsequently created does not display a marked (i.e. easily evidenced) seasonality everywhere. The fact that no marked seasonality of the Algerian Current system has been evidenced yet might be due to the distance from the zones of dense water formation, which could attenuate the signal, and/or to the narrowness of the Strait of Gibraltar, which could limit the inflow and reduce seasonal variations there.

- Numerical models (e.g. [16]) consider that the bifurcation of the AW flow at the entrance of the Channel of Sicily is driven by the channel topography. However, one can also consider that surface waters in the north of the western basin are denser -leading to a sea level lower- than in the south. Hence, AW in the south can tend to flow northwards, obviously alongslope due to the Coriolis effect, hence forming the Tyrrhenian vein whatever the topography of the Channel of Sicily.

- In the Ligurian, the Provençal and the Catalan, AW flows north of the zones where it will finally mix with LIW (see below) and sink (to form the Western Mediterranean Deep Water, WMDW), so that these zones are away from the coast (a better description of the links between the various processes is provided in section 5.1.3). This is a characteristic of all medi-terranean seas so that the generic name of "Northern Current" was proposed [1], with the secondary aim to show that what were called "Ligurian Current", "Liguro-Provençal Current" and "Catalan Current", were only parts of a unique entity and, more generally, of the western gyre. In addition, fig. 1 clearly shows that what is called the Northern Current can in fact be identified continuously from the southern Tyrrhenian up to the Alboran.

- In the Ligurian and the Provençal, the Northern Current is characterised by maximum speeds of several $10 \mathrm{~cm} / \mathrm{s}$ in its core, a width of a few $10 \mathrm{~s} \mathrm{~km}$ and a thickness of a few 100s m. Since AW is denser there than in the south, the Northern Current is narrower and deeper than the Algerian Current [15]. However, it displays 
a marked seasonal variability (due to the links with the dense water formation process above mentioned), being more intense, narrower and deeper in winter [17]. The Northern Current does not develop marked instabilities in either the Tyrrhenian or the Catalan while small eddies have been described west of Corsica $[12,15]$. In the Ligurian and the Provençal, it only develops, in winter mainly, meanders that have never been observed to evolve into structured eddies [15, see section 3.2]. Episodically, it can generate, at the border between the Ligurian and the Provençal, a branch ${ }^{12}$ first evidenced by [18]. The zone where dense water forms is characterised by mesoscale currents that are relatively weak in summer and intense (a few 10s cm/s over the whole depth) in winter [19]. Dense water sinks within small-scale (a few $\mathrm{km}$ in diameter) plumes can be of $\sim 10 \mathrm{~cm} / \mathrm{s}$ (so that less dense waters are uplifted), but the overall sinking speed is $\sim 1 \mathrm{~mm} / \mathrm{s}$ only [20]. Sinking water reaching the bottom can lead there $(\sim 2000 \mathrm{~m})$ to horizontal currents as large as several $10 \mathrm{~s} \mathrm{~cm} / \mathrm{s}$ [21].

- The Gulf of Lions itself is in fact a semi-circular continental shelf so that most of the Northern Current flows as a major vein along the upper part of the continental slope, i.e. along its diameter [22]. When the Mistral (Mi) does not prevent its upper part from following the coast and partly penetrating over the shelf, this part tends to flow as a minor vein around the whole gulf (both veins join at the exit of the gulf). In such a situation, the Northern Current combines with the natural tendency (again due to the Coriolis effect) of any river outflow to be deflected on the right, so that waters from the Rhône are entrained around the whole gulf. When the Mistral and the Tramontane (Tr) blow, they mix and spread seawards the Rhône waters (similar effects occur with westerly winds on the Ebro waters, as opposed to the Bora/Pô interactions, see below). In the northern and northwestern parts of the gulf, these winds induce 6 upwelling cells during stratified conditions [23] and, in winter, shelf dense water formation (maybe occurring with a similarly discontinuity). It must be emphasised that the canyons that cut the continental slope do not "attract" dense water formed in the coastal zone: they only operate as

12 The term "branch" is used to figure a flow spreading seawards, ramifying as a tree branch, and finally vanishing in the central part of a subbasin (contrary to a vein that follows the topography). 
"sediment traps", allowing dense water entrained over the shelf whatever its direction to be trapped and set in position to reach greater depths.

- Where AW closes its western gyre, i.e. along the Spanish coast near the border between the Alboran and the Algerian, the (old) water that has skirted the whole basin (and is thus markedly modified) encounters the water that has just flowed in. Hence, large horizontal gradients occur there. When incoming AW forms a second clockwise gyre in the eastern Alboran, it entrains older AW, roughly from Almeria, Spain, to Oran, Algeria. Since the incoming flow is more intense, it forms the AlmeriaOran jet that is well delimited on its left-hand side by the Almeria-Oran front.

- The various islands and their associated shelves have significant effects. The Algerian eddies blocked by the Sardinian and Tunisian converging shelves often entrain AW southwards off western Sardinia (together with other anticyclonic eddies [12] and with the northwesterlies-induced drift), while AW released by the eddies' decaying in the north is constrained to flow northwards off western Corsica. The marked orography of both Sardinia and Corsica also protects most (the remainder) of the Tyrrhenian, and reduces there the mixing and cooling by the westerlies. In winter, the Balearic Islands first protect from the northwesterlies AW entrained by the AEs, so that AW can progress northwards quite easily up to the islands which somehow fix the position of the North Balearic front in the west [24]; they also lead part of the Northern Current to form a vein flowing north of them in the Catalan.

- In addition, the marked orography of both Sardinia and Corsica creates a funnelling effect for the westward winds that are the continuation of both the Mistral and the Tramontane. In the western Tyrrhenian, just east of the Strait of Bonifacio (between Sardinia and Corsica), such a specific wind field induces (due to the Coriolis effect) a mesoscale dipole with an anticyclone in the south and a cyclone in the north that have very different structures. The anticyclone (not clear in Fig. 1) is composed of (warm) AW converging (depression of the interface between AW and MW) and rotating as an isolated eddy. The cyclone (relatively large in Fig. 1) results from AW diverging (uplifting of the interface) and forming in fact a ring that surrounds a cool zone (of MW), which is the main feature seen in Fig. 1 and which 
has recently been hypothesised to be an occasional zone of dense water formation [25]. These differences between the anticyclone and the cyclone induced east of Bonifacio by the westerly winds are in fact representative of most of the differences between the previous understanding(s) of the circulation in the eastern basin and our own understanding (see section 5).

\section{$3.2 \mathrm{AW}$ in the eastern basin}

In the Channel of Sicily the circulation of AW is complex, due to the necessary bifurcation between the western and the eastern basins, to the complexity of the topography with numerous islands and banks, and to the large width of the channel. It cannot be easily studied with SST images (Fig. 1 is not very explicit), due to the intense mixing by the topography and the northwesterlies, to the upwelling these winds induce off Sicily, and to the southward heading of the flow that rapidly warms. In addition, it cannot be easily studied with in situ data because of the intense fishing activity and the existence of half-channel national economic waters. Therefore, AW within the channel has been said to flow mainly either in the eastern side (as a Sicilian vein, e.g. [27]) or in the western side (as a Tunisian vein, e.g. [28]).

At the exit of the channel, SST images suggest (although not clear on Fig. 1) that three kinds of processes occur or have occurred, so that the eastern gyre at its beginning is split into several components. One is a northeastward-spreading branch that we associate with interannual variability (it disappeared in early 1998), while it has been qualified as a permanent meandering stream by e.g. [5]. The second is the generation of mesoscale eddies that tend to drift in the central part of the Ionian. The third is a more regular flow (the south-Tunisia vein) that, for most of it, follows the edge of the Tunisian shelf and, for a minor (and upper) part of it, follows the Tunisian coast (as in the Gulf of Lions); both parts of this vein join off Libya, the Tunisian vein hence becoming a Libyan vein. The term of vein(s) is justified by the fact that AW spread in the central part of the Ionian (as a branch and/or eddies) will join it downstream to form the eastern gyre stricto sensu. Note that the famous tourists places that are the Kerkennah and Djerba Islands are among the coldest spots in winter, due to the very shallow shelf there 


\section{Circulation in the Mediterranean}

(somewhere a few metres only). As first hypothesised by E. Salusti (pers. com.), these shelf waters most probably tend to sink, as indicated for the Gulf of Lions and as it will be shown for the northern parts of both the Aegean and the Adriatic. From $\sim 15^{\circ} \mathrm{E}$, the Libyan vein continues alongslope eastwards and appears unstable, generating mesoscale eddies that are smaller and less well organised than the Algerian ones and that rapidly detach from the coast, due to the topography (isobaths spreading seawards). These eddies, together with those created just at the channel exit that drift in the central Ionian, form a complex eddy field in the whole southern Ionian. The Libyan vein continues alongslope in the Gulf of Syrta (GoS) without developing large mesoscale instabilities there (maybe due to a flow too reduced and/or to a topography too shallow).

Since most of the eddies are trapped within the southern Ionian while only few of them drift into the Cretan (Cre), it might be that they decay in the southern Ionian before joining the Libyan vein, together wit the water spread in the interannual branch and then released. The eastern gyre hence restructures itself along the northern Cirenaïca (Cir), in the same way as the western gyre near $0^{\circ}$ (the parallel with Alboran and western Algeria, and more generally between the western and eastern basins, is detailed in subsection 5.1). From northern Cirenaïca to the western part of the Nile delta, what can be named the "Libyo-Egyptian Current" (the counterpart of the Algerian Current) generates well structured and energetic eddies that appear very similar to the Algerian ones. These anticyclonic eddies can be large (150-250 km), and they propagate downstream not faster than $\sim 3 \mathrm{~km} /$ day, i.e. generally slower than the Algerian eddies. As already shown off Algeria, it is expected that the Libyo-Egyptian eddies sometimes extend down to the bottom and can be guided, at least for the largest and most energetic ones, by the deep isobaths $(\sim 3000 \mathrm{~m})$ associated with the Herodotus trough southeast of Crete (see Fig. 4).

There, they can interact with Ierapetra, the anticyclonic eddy generated by the Meltem $^{13}(\mathrm{Me})$ southeast of Crete together with Pelops generated southwest of the Peloponnese (Pel). Both eddies are clearly recognised in Fig. 1, Ierapetra having drifted

\footnotetext{
${ }^{13}$ The Meltem is a northerly wind blowing almost continuously in summer, hence also named "the Etesians".
} 
south from where it was created $\sim 6$ months earlier. We have shown that Ierapetra is actually created every summer by the Meltem close to the southeastern tip of Crete. It can then remain stationary for one year (being thus reinforced the year after), drift southwards as far as the Libyo-Egyptian continental slope (hence interacting with the Libyo-Egyptian Current), or drift westwards as far as the western tip of Crete. Hence, Ierapetra can survive for years, successive Ierapetra's can coexist, possibly merge, and often interact with the Libyo-Egyptian eddies. As evidenced from SST images, the shadowing effect of Crete (high relief) on the Meltem is sensed as far as Africa. Hence, the surface waters entrained southwards on both sides of Crete by this northerly wind tend to flow backward in between and feed Ierapetra. The alongslope circulation of AW can also feed Ierapetra from the south through the Libyo-Egyptian eddies via a paddlewheel effect (and from the northeast as well, see below).

We mainly hypothesise that the spreading seaward of the deep isobaths in the western Levantine leads the (deep) Libyo-Egyptian eddies to separate from their (shallow) parent current that remains alongslope, and that the Herodotus trough traps them. Such a trapping can also apply to Ierapetra. To emphasise the fact that the zone corresponding to the Herodotus trough is characterised by the accumulation and interaction, frequently resulting into merging, of eddies originated from outside the zone, and not by some permanent gyre or eddy created there (previously named MersaMatruh), we name it $\Sigma \mathrm{Lw}_{\mathrm{w}}$ (accumulation in the western Levantine).

Eddies that decay in the $\Sigma \mathrm{L}_{\mathrm{W}}$ zone release AW that, at least partly, rejoins the remainder of the alongslope Libyo-Egyptian Current. Up to the Nile delta, the restructured eastern basin gyre generates medium (50-150 km) anticyclonic eddies that are similar to, although smaller than, the Libyo-Egyptian ones. From the Nile delta up to the southern and central Middle East, instability processes only generate small (up to 50 $\mathrm{km}$ ) eddies and mushroom-like features that rapidly propagate downstream (up to 10 $\mathrm{km} /$ day). Such characteristics might be due to the shallower topography that prevents larger and better-organised features to develop. In any case, these features spread AW seaward and feed what was known as the Shikmona zone that we name $\Sigma L_{E}$, for reasons similar to those invoked earlier for $\Sigma \mathrm{L}_{\mathrm{W}}$ and $\Sigma \mathrm{A}_{\mathrm{E}}$ (accumulation in the eastern Levantine). When these features decay, the released AW re-feeds, at least partly, the 
eastern basin gyre along the northern Middle East slope. Then, along the Turkish slope up to Rhodes, the gyre (previously named Asia Minor Current there) mainly generates sharp meanders, some of which can evolve into medium (50-150 km) anticyclonic eddies that propagate at up to $\sim 3 \mathrm{~km} /$ day. Although a parallel will be made in section 5 with the Northern Current in the western basin, it has been stressed that the latter never generates such eddies.

Then, the Rhodes Island divides the eastern basin gyre into a northwestern vein and a southwestern one. The northwestern vein flows along the Turkish slope most of the year, except maybe in summer when the Meltem blows against it, and penetrates into the Aegean. There, the complex topography induces a second bifurcation with a sub-vein that continues into the Northern-Aegean (Nor-Aeg) and a sub-vein that tends to skirt the whole Southern-Aegean (Sou-Aeg). The former sub-vein joins with the Black Sea outflow and will be densified in winter, hence forming shelf water that will not reach large densities, furthermore since the northward propagation of LIW is mostly prevented by the complex topography (see below). The latter sub-vein is associated with the dense water formation process that involves AW and LIW (see below) to form the Aegean Deep Water (AeDW). Although most of the AW exits the Aegean through the western Cretan Arc (i.e. west of Crete), some of it flows north of Crete, as evidenced by medium-sized anticyclonic eddies propagating eastwards (i.e. downstream) before decaying. Then, AW that has skirted the Southern-Aegean in such a way feeds, through the passages between the islands that constitute the eastern Cretan Arc, the southwestern vein that continuously flows along the southern slope of these islands. In winter, the southwestern vein is associated with the formation of LIW southwards of Rhodes, as is the Northern Current with WMDW. In summer, when the Meltem prevents AW from flowing markedly into the Aegean (and induces a marked upwelling zone off Turkey), the southwestern vein constitutes most of the eastern basin gyre. It can be identified as far as Crete, sometimes clearly feeding Ierapetra. But then, it is generally entrained in $\Sigma \mathrm{Lw}_{\mathrm{W}}$ and again around the eastern Levantine. Therefore, whatever the season and the balance between the northwestern and southwestern veins, the eastern basin gyre is generally not encountered along the southern slope of Crete, so that most AW definitively exits the Levantine via the Aegean west of Crete. 
AW then skirts the Peloponnese. In summer, part of it forms the wind-induced Pelops that can later drift up to a few 100s km westwards. The remainder, and most AW during the rest of the year, continues northwards in the northeastern Ionian where it reconstitutes the eastern gyre before bifurcating into a northern and a western veins at the entrance of the Adriatic. The northern vein penetrates into the Adriatic and is partly associated with the formation of the Adriatic Deep Water (AdDW, see below) in the southern part of the subbasin (Sou-Adr), while the remainder continues northwards and mixes there (Nor-Adr) with the Pô and other rivers runoffs. There are similarities between the Aegean and the Adriatic, since less dense water is formed on the shelf in the north and denser water is formed offshore in the south. There are differences between the Bora effect on the Pô outflow (similar to the Meltem effect on the Nile outflow) and that of the Meltem on the Black Sea outflow (similar to the Mistral and westerlies effects on the Rhône and Ebro outflows), since the Bora pushes the Pô outflow towards the coast, so that it remains well structured along most of the Italian peninsula. AW exiting the Adriatic rejoins the westward vein that bypassed the Adriatic, both continuing along the southern tip of the Italian peninsula and Sicily, before closing there the circuit of the eastern basin gyre. The Maltese filament, formed by cold water upwelled off southwestern Sicily, then separates the incoming AW from the older one. It can be detected in the whole southern Ionian and can be considered as a tracer of the front that is the counterpart of the Almeria-Oran front.

\section{The circulation of the intermediate and deep waters (fig. 3,4 )}

To our knowledge, recent schemas of the circulation of the intermediate and deep waters have been proposed (and validated) for the western basin only [9]. Those proposed hereafter for the eastern basin must hence be considered as a first attempt to analyse the available in situ data sets with general ideas validated in the western basin only. These general ideas attribute a major role to the Coriolis effect and to mesoscale eddies, be these eddies either wind-induced or generated by the instability of the alongslope AW circulation. The in situ data collected in the eastern basin (mainly in the north) were analysed up to now with concepts that are very different from ours, so that 


\section{Circulation in the Mediterranean}

the analysis hereafter is not consistent with the previous ones ${ }^{14}$. Even though this analysis describes features in the south of the eastern basin that cannot be supported by data unavailable yet, so that these features are hypothetical, the present tense is used and adverbs such as "probably" are mostly omitted for convenience. In addition, we consider that the circulation of intermediate and deep waters necessarily displays a seasonal variability more or less far away from the zones of formation; however, due to the lack of data, this seasonal variability is not represented in the schemas.

Several places and processes of formation have been hypothesised for LIW, including the interior of mesoscale anticyclonic eddies all year long in the southern Levantine. However, it is formed mainly south-southeast of Rhodes in the northern Levantine, according to the offshore wintertime processes described in section 1 (see also section 5). As already said, LIW is the MW produced with the largest volume. Since it is the warmest and saltiest water formed in the whole sea, it can easily be tracked up to Gibraltar just below AW. Other intermediate waters formed together with denser waters, as e.g. in the Aegean (named Cretan Intermediate Water) or in the LiguroProvençal (named Winter Intermediate Water), cannot be differentiated so easily from waters above or below and they represent much lower amounts. We thus only discuss hereafter (section 4.1) the circulation of LIW, i.e. the intermediate water produced in the northern Levantine (Fig. 3).

Some deep waters might be occasionally produced in specific places. This was said [29] for a water that reached $\sim 2000 \mathrm{~m}$ in the northern Levantine where most of LIW forms. This was also said [25] for water denser than TDW (see section 4.2) that could be formed east of Bonifacio (cool zone in fig. 1) and could fill the deep Tyrrhenian (down to $\sim 3500 \mathrm{~m}$ ). However, we do not have enough data about these deep waters so that we restrict ourselves to the discussion (section 4.2) of AeDW, AdDW, TDW and WMDW (Fig. 4).

${ }^{14}$ In any case, there are a lot of discrepancies between these previous analyses too! 


\subsection{LIW}

LIW formed in the northern part of the Levantine flows, due to the Coriolis effect, along the southern continental slope of the Cretan Arc islands, from Rhodes to Crete and to the Peloponnese. Because the sills between these islands reach depths larger than the 100-500 m LIW level, some LIW penetrates into the Southern-Aegean where it mixes with AW in winter to form AeDW (it hardly penetrates into the Northern-Aegean, due to the complex topography). However, the section of the openings does not allow the whole volume of LIW to go through so that most LIW flows alongslope south of Crete. Ierapetra and Pelops wind-induced eddies entrain LIW where they form (i.e. close to the coast and just above the continental slope where LIW flows) and then transport it seawards, potentially over $100 \mathrm{~s} \mathrm{~km}$, releasing it away from the slope, in a process similar to the one mentioned in section 2.2 for the entrainment of LIW from the slope of Sardinia by the Algerian eddies passing by. The occurrence of LIW within such eddies when in the southern Levantine might have been misinterpreted as a formation of LIW within offshore eddies. Note that the Libyo-Egyptians eddies (counterparts of the Algerian eddies) are in a position too far south to allow them to entrain newly formed LIW. Part of the LIW that continues circulating along the northeastern slope in the Ionian penetrates into the Southern-Adriatic where it mixes with AW in winter to form AdDW. The remainder bypasses the Southern-Adriatic and continues alongslope as far as the Channel of Sicily, where most of it (sill at $\sim 400 \mathrm{~m}$ ) outflows into the western basin. However, any part of LIW that has bypassed the entrance of the channel and is still associated with an alongslope pressure gradient will continue alongslope around most of the eastern basin. In other words, waters are generally not "attracted" by the openings and they do not "feel" them; they circulate alongslope, as long as they are forced to do so by an alongslope pressure gradient, and hence they can "miss" the openings.

Within the Channel of Sicily, LIW flows along the Sicilian slope and then skirts Sicily. This path, initially suggested by [30], is now generally agreed and supported by theoretical analyses 


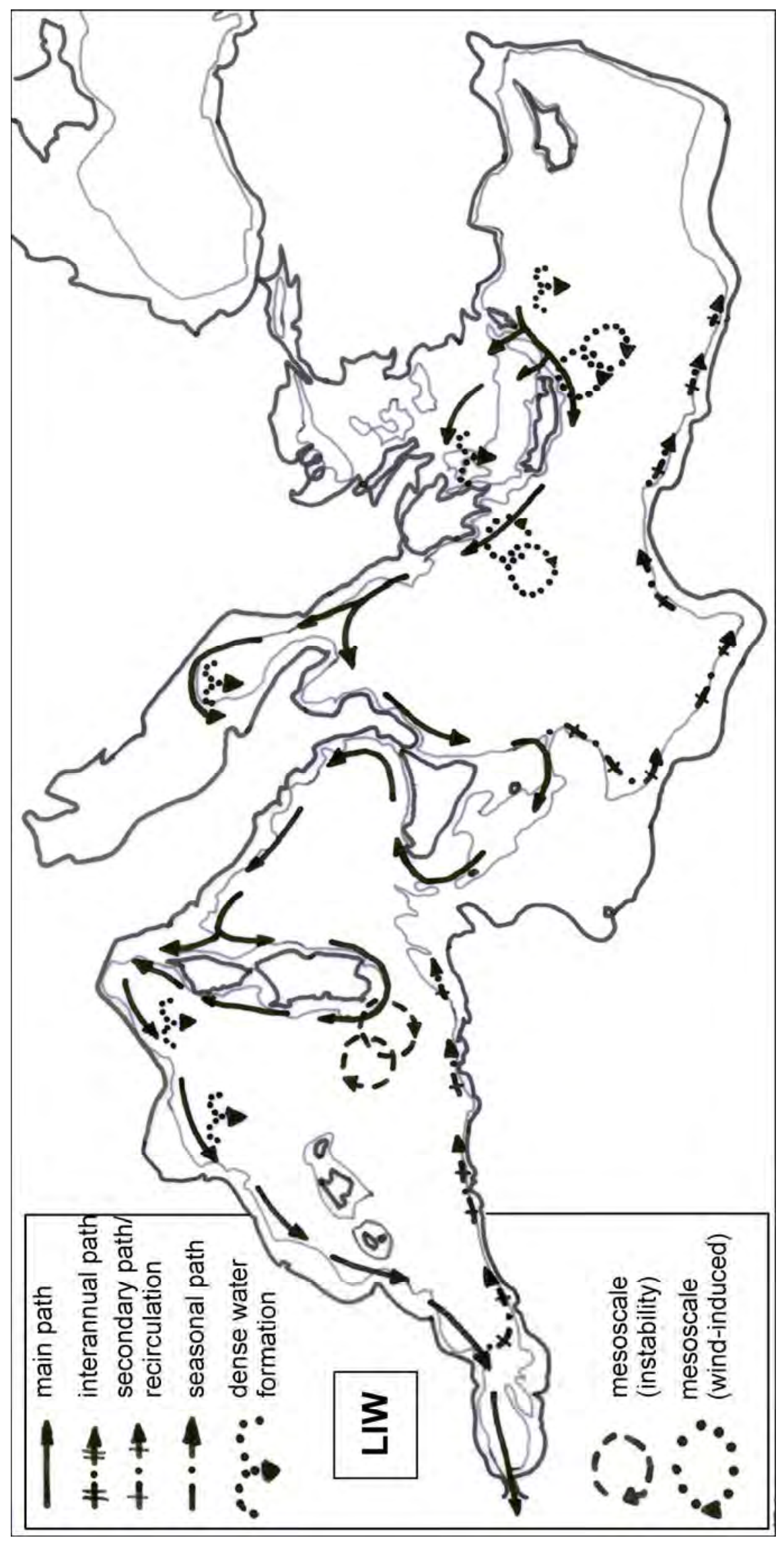

Fig. 3. Circulation of LIW extrapolated from [9] for the western basin. The thin line represents the 500-m isobath. 
(e.g. [31]). Then, LIW mainly circulates around the Tyrrhenian, roughly at 200-600 m. A vein flows out through the Channel of Corsica (sill at $\sim 400 \mathrm{~m}$ ) while the remainder continues and flows out through the Channel of Sardinia. When this vein enters the Algerian, part of it can be entrained seawards by Algerian eddies passing by and then be released in the central subbasin. The remainder of the vein continues alongslope along western Sardinia and Corsica, joins with the vein issued from the Channel of Corsica, and then participates with AW in the wintertime formation of WMDW in the Ligurian and the Provençal. The still-recognisable LIW continues along the Spanish slope and most of it outflows through the Strait of Gibraltar (sill at $\sim 300 \mathrm{~m}$ ), where it can still be recognised along the Spanish slope, while the remainder that bypassed the opening then progresses alongslope off Africa (as discussed for the entrance of the Channel of Sicily).

Therefore, LIW appears to play a major role in the functioning of the Mediterranean Sea. First, because it is the warmest and saltiest MW formed with the largest amount. Second, because it mainly flows along the northern continental slopes of both basins just below AW, thus being involved there in the offshore formation of all deep MWs (AeDW, AdDW, WMDW). Because the immersion of LIW allows it to flow rather easily through the major openings, its path is almost one-way, from the northern Levantine to the Channel of Sicily and the Strait of Gibraltar. However, the parts of LIW that have bypassed either the Channel of Sicily or the Strait of Gibraltar continue flowing alongslope around the basins. In addition, being involved into wintertime processes all along its path, one expects that LIW displays everywhere an increasingly complex seasonal variability (see also section 4.2).

\subsection{AeDW, AdDW, TDW and WMDW}

AW is warmer and saltier in the Aegean than in the Adriatic since northerlies are less cold (the Adriatic is surrounded by the Alps) and it just starts to be diluted (by the Black Sea mainly; it will be more and more diluted by rivers outflows). Moreover, LIW is warmer and saltier in the Aegean than in the Adriatic since it is closer to its formation zone and hence has undergone less mixing. Therefore, AeDW is saltier and warmer than AdDW. However, both waters have roughly similar densities. Up to the eighties, and nowadays as well, AdDW was denser than AeDW while, during what has been called "the 


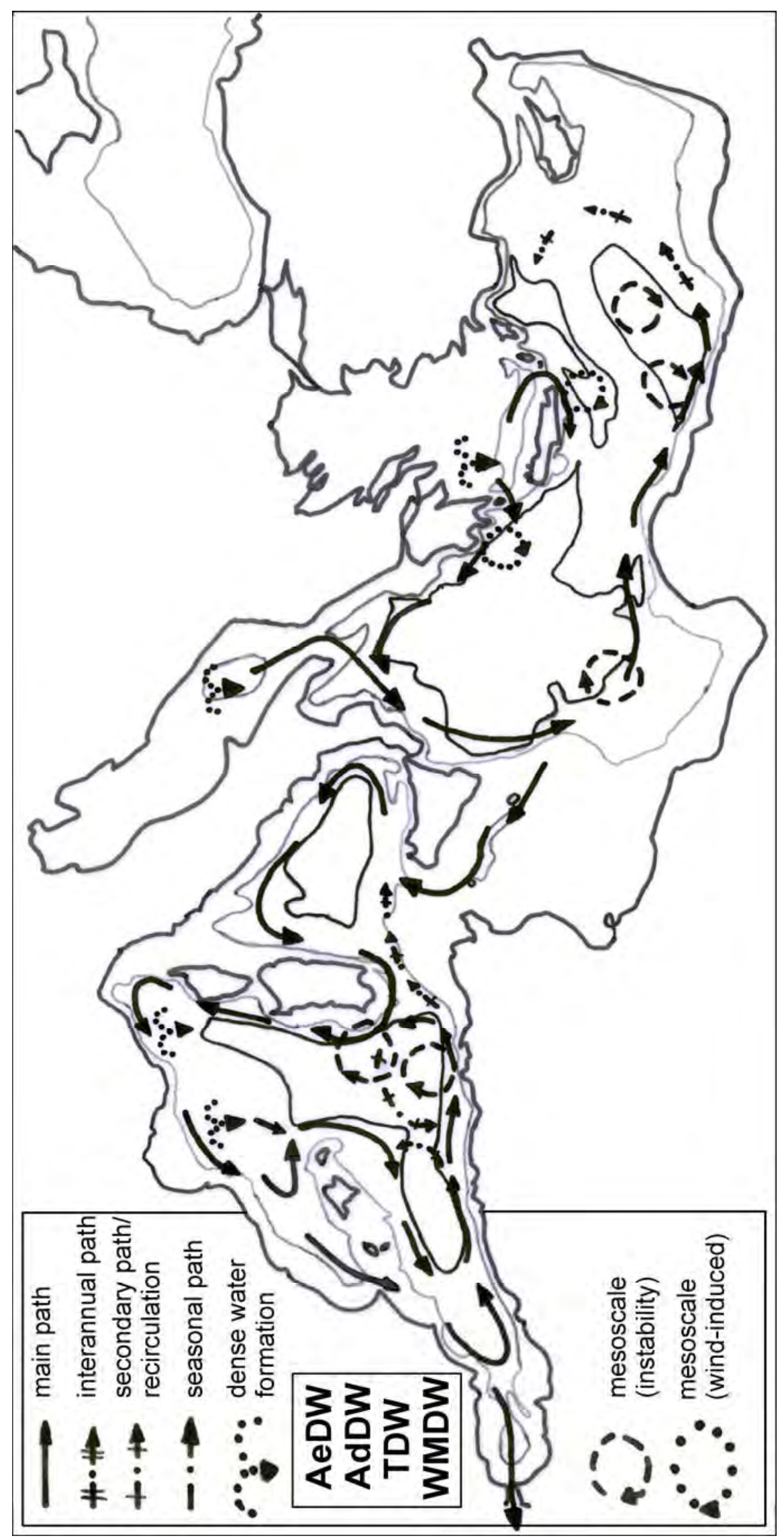

Fig. 4. Circulation of AeDW, AdDW, TDW and WMDW extrapolated from [9] for the Western Basin. The thin lines represent the $1000-\mathrm{m}$ and $2750-\mathrm{m}$ isobaths 
transient" (see [32], for a review), the reverse occurred. These two deep waters first accumulate in the troughs (1000-1500 m) over which they are formed (in the SouthernAegean and Southern-Adriatic, resp.) before outflowing through the various openings. From there, they cascade in the northern Levantine, northern Cretan and northern Ionian, down to depths where the density they got due to mixing is that of the resident waters. Then they circulate alongslope, due to the Coriolis effect, as long as they are forced by an alongslope pressure gradient, hence tending to describe a counterclockwise basin-wide gyre. Note that these cascadings of AeDW and AdDW occur from sills at $\sim 1000 \mathrm{~m}$ that are markedly below the LIW mean level (the LIW gyre is not disturbed by these outflows).

Two sources of deep waters, located in two relatively enclosed and shallow subbasins (the Aegean and the Adriatic), thus compete to fill the greatest depths of the eastern basin (4000-5000 m) that must hence be considered as a trap for the densest waters. However, since these deep waters are produced every winter, their upper (i.e. less dense) part must outflow through the Channel of Sicily. Deep water that initially cascaded down to a given level will reach upper levels (years or decades later) only after having mixed all over the basin with the waters above or after having been uplifted by denser waters, whatever their origin. It is generally assumed that the deeper the level the weaker the stratification and the circulation, which is verified only on average and away from the zones of dense water formation due to a long-lasting mixing. However, the densest waters formed in any of these zones, even during short periods and in small amounts, can reach the bottom, hence being prevented from intense mixing with surrounding waters and circulating significantly to find their equilibrium level; these bottom waters [33] have hydrological characteristics that vary interannually.

The upper part of AeDW and/or AdDW that outflows through the Channel of Sicily is located in the deeper part of the channel, mainly on the Tunisian side. As suggested by [30] and demonstrated later by [31], this results from differences in density and amount between these deep waters and LIW. Whatever, the AeDW/AdDW outflow is much denser than the waters residing in the Tyrrhenian, so that it permanently cascades down to depths of 1900-2000 $\mathrm{m}$ [34], mixing itself and with the resident waters before 
skirting the Tyrrhenian, hence initiating a basin-wide gyre, and entering the Channel of Sardinia (sill at $\sim 2000 \mathrm{~m}$ ) close to Sardinia. The flow from the Tyrrhenian to the Algerian (Tyrrhenian Dense ${ }^{15}$ Water, TDW), although being partially composed of waters having entered the Tyrrhenian from the Algerian (see below), is thus mainly composed of waters from the eastern basin. The origin(s) of the waters found in the deep Tyrrhenian (2000-3500 m) is/are still debated since none of those hypothesised up to now (the Algerian subbasin, the eastern basin or the zone east of Bonifacio) has been supported by definitive data sets. From the Channel of Sardinia, either TDW is entrained seawards (as LIW) by Algerian eddies passing by or it continues alongslope towards the Ligurian and the Provençal. WMDW being formed there over relatively great depths (2000-2500 m), then mixes or flows together with TDW as a continuation of the basin-wide gyre in the Catalan, the Alboran and the Algerian.

WMDW describes a basin-wide gyre that is strongly dependent on its density and on the topography. Where depths are as large as 2700-2900 m, which occurs only in the western and eastern parts of the Algerian (not considering the Tyrrhenian), the densest WMDW is trapped, thus possibly describing two sub-gyres that have recently been evidenced there $[36,3]$. These sub-gyres are generally associated with speeds of several $\mathrm{cm} / \mathrm{s}$ that can be locally larger due to the topography since annual means of $\sim 10 \mathrm{~cm} / \mathrm{s}$ were measured at $\sim 2700 \mathrm{~m}$ off Algeria [3]. Note that a link probably exists between the counter-clockwise circuit followed by the Algerian eddies in the eastern Algerian mainly [12] and this deep topography. For depths of 2000-2700 m, the Channel of Sardinia traps the less dense WMDW in the western part of the basin, thus forcing it to skirt the whole Algerian before possibly flowing back into the Ligurian and the Provençal. At depths shallower than $\sim 2000 \mathrm{~m}$, WMDW preferably exits the Algerian through the Channel of Sardinia into the Tyrrhenian, possibly together with TDW that has skirted the whole western basin.

In the southern Tyrrhenian, and at less than $\sim 2000 \mathrm{~m}$, these western waters will possibly, and maybe intensively, mix with, and/or be uplifted by, those cascading

15 The term dense is used instead of deep to specify that i) this water is not the deepest one found in the Tyrrhenian and/or that ii) it is not essentially formed by a classical offshore wintertime formation process such as the one hypothesised in the east of the Strait of Bonifacio. 
permanently from the Channel of Sicily, hence having one more possibility than the deep eastern waters to reach shallower levels (the latter only having the possibility to mix over the whole basin and be uplifted by recently formed denser waters). In addition, [35] have hypothesised that waters can be sucked by a Bernoulli effect at the Strait of Gibraltar (sill at $\sim 300 \mathrm{~m}$ ) from depths down to $\sim 700 \mathrm{~m}$, a process that probably does not occur at the wider Channel of Sicily. Therefore, both the cascading from the Channel of Sicily and the sucking from the Strait of Gibraltar account for a conveyor belt in the western basin (not considering the deepest part of the Tyrrhenian) shorter and more intense than in the eastern basin. Whatever, the densest waters are found on the deeper and left-hand (Moroccan) side of the Strait of Gibraltar while LIW is found on right-hand (Spanish) side, probably for reasons similar to those invoked for the Channel of Sicily.

\section{Discussion}

Most of the physical oceanographers see more differences than similitudes between the two basins of the Mediterranean Sea. Because we believe in the contrary since more than one decade [1] and think that specifying the similitudes (and differences!) can lead to a better understanding of the phenomena in both basins, we focus our discussion on this point.

Before that, we think instructive to specify what are, according to us, the reasons that led to overviews of the circulation in the sea so different and, more especially, to views of the circulation in the eastern basin so different, with AW said to mainly cross [e.g. 4, 5] or skirt [6, 7] that basin. The main reason, we believe, is that although we use average remotely sensed (e.g. Fig. 1) and in situ (e.g. [3]) data as most of our colleagues, we take care of visually analysing individual satellite images (day after day if not track after track, e.g. [7]), of locating CTD stations only few $\mathrm{km}$ apart based on images received onboard in near real time (e.g. [3]), and of simultaneously collecting current time series as numerous (up to $30-40$ ) and long (up to 1 year) as possible (e.g. [3, 17, 37]). 
Just looking at one single (good and representative) image evidences, for instance, the fact that important dynamical processes are occurring in the south of the basins, which has motivated our former interest for the Algerian subbasin, now motivates our interest for the southwestern Levantine ... and explains how surprised we have been not to see any information specified along most of the African coast in the eastern basin by e.g. [4] and [5]. In addition, looking at series of daily images allows following continuously mesoscale phenomena over years (which is not possible with e.g. altimetric data) and analysing small-scale features (e.g. shear eddies, filaments, gradients), which gives us a "specific-although-maybe-subjective feeling" that can hardly be achieved with the analysis of CTD data and/or numerical simulations. To better explain the other disagreements that exist about the eastern basin, let us specify our personal understanding of these mesoscale phenomena.

For us, a mesoscale anticyclone (be it wind-induced, as Ierapetra and Pelops, or generated by the instability of an alongslope current of AW, as the Libyo-Egyptian eddies) is basically an isolated rotating piece of (warm) AW "floating" on MW and able to move, interact up to merge with others and finally decay, hence releasing the piece of AW. Such an anticyclonic eddy of AW can create an associate anticyclonic eddy of MW as in the Algerian (via pressure, we believe) and possibly over the whole depth [3], making it sensitive to the deep topography (not felt by the 100-200-m deep alongslope circulation of AW). On the contrary, a mesoscale zone cooler than the surroundings and induced by the wind is nothing else that MW (or denser/cooler AW) locally reaching the surface, potentially associated with AW flowing cyclonically (due to the Coriolis effect and geostrophic adjustment) more or less all around it as a ring (as is generally thought for e.g. what is called the "western Cretan eddy") or, more probably, along its coastal side mainly (what we believe is a characteristic of what is called the "Rhodes gyre"). Whatever, we do not consider such cool zones as isolated pieces of any kind of water able to move, although they can have specific dynamics (as where dense water is formed), so that such zones are neither eddies nor gyres (as we defined them). In addition, note that these cool zones are associated with an upwelling just when they are created, in relation with the uplifting of the interface between AW and MWs. Then, they are just more and more homogenised, and surface water there is densified, possibly up to sinking in late winter (see section 5.1.3), so that the average speed there is 
downwards; these nutrients-enriched zones start to be productive (spring blooms) as soon as stratification takes place, thus allowing light to be available for a sufficient period of time. Other cyclonic features such as the eddies induced by the instability of a current $[10,26]$ or by the shear on its edge [14] are in fact small (up to a few $10 \mathrm{~s} \mathrm{~km}$ ) and short-lived (up to a few weeks). Therefore, instead of considering that the variability at mesoscale is due to alternated cyclones and anticyclones (as commonly done up to now by e.g. analyses of altimetric data), we consider that the mesoscale eddy field is mainly composed of anticyclones that are often juxtaposed (hence roughly twice as large as defined according to altimetry!).

\subsection{The dynamical phenomena}

Although the western and eastern basins are different, they display marked similarities, not only at basin scale (5.1.1) but also at subbasin scale (5.1.2). After having analysed the offshore dense water formation process (5.1.3), it appears that there might be another way to consider the functioning of the sea (5.1.4). In any case, the Coriolis effect and the mesoscale variability are basic mechanisms that also allow explaining the circulation in the Black Sea (5.1.5). However, observing the circulation is complicated everywhere by the occurrence of other types of currents (5.1.6).

\subsubsection{Similarities and differences at basin scale}

First, both basins act as machines that essentially salt and additionally cool (i.e. densify) AW to form several types of MWs. The alongslope counterclockwise circulation of AW describes two basin-wide gyres. Parts of both gyres are markedly unstable in the south, leading to specific current systems, while they are more stable in the north where AW sinks in winter, mainly offshore. MWs formed in both basins must outflow over relatively shallow sills.

However, the two basins are different with respect to AW, mainly because they are located in series, i.e. one after the other. The western basin is a transitory domain for most $(\sim 3 / 4)$ of the AW, including some AW first entrained in the western gyre without 


\section{Circulation in the Mediterranean}

sinking that can then enter the eastern basin, while the eastern basin is a definite cul-desac for that AW. The two basins are also different with respect to MWs because the eastern MWs that must exit the basin can be only the shallowest ones (a few 100s m), so that the densest can be trapped for a long time. On the contrary, most of the dense western MWs (down to $\sim 2000 \mathrm{~m}$ ) continuously mix and/or are uplifted by the eastern MWs that cascade from the Channel of Sicily, both having to exit the western basin at Gibraltar. Therefore, the deep (down to $\sim 2000 \mathrm{~m}$ at least) circulation is more intense in the western basin than in the eastern one.

\subsubsection{Similarities and differences at subbasin scale}

In this subsection, we consider the eastern basin without the Aegean and Adriatic subbasins.

The basin entrance (i.e. before a relatively structured basin-wide gyre forms) can be considered as narrower in the west (the Strait of Gibraltar and the Alboran,) than in the east (the Channel of Sicily and the Ionian). Hence, constrain of the AW inflow is more intense at the western entrance and leads to circulation features in the Alboran that, although complex, are simpler than in the Ionian. However, although the Alboran and the Ionian are very different in shape and size, they are paralleled because they are i) located upstream from where the basin-wide gyres start to be structured (even if unstable), i.e. off western Algeria and Cirenaïca and ii) not concerned by the dense water formation process that occurs offshore in the north.

Then, we see marked similarities between the Algerian and the Cretan + western Levantine. Indeed, the AW flow, rather well defined alongslope in the western parts of these subbasins, then creates specific current systems (the Algerian and the LibyoEgyptian) that generate large (up to $150-250 \mathrm{~km}$ ) long living (several months/years) deep (several 1000s m, sometimes down to the bottom) anticyclonic eddies that first propagate (at a few $\mathrm{km} /$ day) downstream (i.e. eastward). Probably because these eddies are deep and tend to be guided by the deepest isobaths, while their thinner parent current flows along the upper part of the continental slope, they generally follow a circuit in the eastern Algerian (where the deeper part can accommodate several eddies) 
and accumulate up to merging over the Herodotus trough (which width is hardly larger than a typical eddy diameter). Together with not so deep eddies that might be entrained southwestwards by the $\beta$-effect (variation of the Coriolis effect with the latitude) and non-linearities [14], they possibly come back towards the southern coast and interact with their parent current.

The similarity between the Tyrrhenian and the eastern Levantine is motivated by the fact that the circulation in these far eastern zones is clearly alongslope. It is relatively stable in the Tyrrhenian and only slightly unstable in the eastern Levantine (as compared to the Cretan + western Levantine). Most of both subbasins are protected from the westerly/northerly winds, either by the Sardinia and Corsica orography and/or by the distance from the windy areas, so that offshore waters are relatively light (not too cooled) and unmixed there.

We see a marked similarity between the Northern Current in the Ligurian, the Provençal and the Catalan, and what was named the Asia Minor Current (and its prolongation as far as Crete at least), even though the former only meanders while the latter can generate medium anticyclonic eddies. Another major similarity is obviously the zone of formation of WMDW in the western basin and that of LIW in the eastern one.

These overall similarities between the western and eastern gyres and their stability/instability characteristics are hidden mainly by the complexity of the northern coastlines in the eastern basin that prevents from having, as in the western basin, an eastern basin-wide Northern Current (that would flow continuously alongslope from Middle East to Sicily). These similarities are also hidden by the fact that Algerian eddies are prevented from exiting the Algerian basin by Sardinia and Corsica, so that the northward spreading of AW they induce has a major importance in the western basin: a significant amount of AW is maintained close to the zone where WMDW forms, which leads to the North Balearic Front and then to a significant vein of AW west of Corsica. Comparatively, AW first spread northward by the Libyo-Egyptian eddies is not forced to accumulate there and not maintained close to the zone where LIW forms, so that it can be entrained southward by the Etesians and then re-feed the basin-wide gyre (without forming any front and vein west of Cyprus). Therefore, although the latitudinal extent of 
the Algerian, the Provençal and the Ligurian is larger than that of the Levantine, the studies of the major processes occurring in the south (generation of mesoscale eddies) and in the north (dense water formation and associated circulation) can be more easily decoupled in the eastern basin than in the western one

There might also be similarities for MWs at subbasin scale. Circulation can be intense at greater depths in both the western and the eastern basins where dense waters recently produced spread, even away from the zones where they were formed. Significant time series have not been collected in all subbasins yet but yearly means of several cm/s might not be exceptional values. The deepest parts of both basins (3000$3500 \mathrm{~m}$ in the Tyrrhenian, 4000-5000 $\mathrm{m}$ in the Ionian and the Levantine) are certainly the quietest (as demonstrated by the occurrence of brine lakes in the east). Densest waters in these subbasins stagnate there for a long time, until they are either mixed through diffusion (permanent but moderate) or uplifted by denser water (occasional but efficient).

Finally, let us comment on the similarities and differences of the dipoles induced by orography and wind funnelling that essentially consist in an actual anticyclonic eddy (of AW) associated with a cool zone (of MW or denser AW). The northwesterlies blowing through the Gulf of Lions (between the Pyrenees and the Alps) generate a small eddy (in the Catalan) and a large cool zone (in the Provençal and the Ligurian where WMDW forms). The westerlies blowing through the Strait of the Bonifacio (between Sardinia and Corsica) generate a small eddy (northeast of Sardinia) and a limited although permanent cool zone (where dense water formation has been hypothesised). The northerlies blowing through the channel west of Crete (between the Peloponnese and Crete) generate a large eddy (Pelops) and a limited cool zone (often named incorrectly "western Cretan eddy"). These northerlies blowing through the channel east of Crete (between Crete and Turkey) generate a large eddy (Ierapetra) and a large cool zone (in the northern levantine where LIW forms). The differences between the basins (zones in the east less cool than in the west, eddies in the east larger and more long-lived than in the west) and within the basins (zones known as major places for dense water formation or not) must not hide the similarities between these wind-induced phenomena. 


\subsubsection{The offshore dense water formation process}

Let us now discuss the links we make between the zones where AW sinks and the currents in the northern parts of the basins that surround these zones "just north" of them. Let us imagine the theoretical case of a basin originally filled with a unique homogeneous water mass. When winter comes, northerly winds cool and evaporate this original water mainly off the northern coasts. Indeed, air masses becoming warmer and wetter while transported over the sea become less and less efficient leeward for dense water formation. The water being made denser mainly in the north of the basin tends to sink there, a process named convection (not downwelling although opposed to upwelling), and the surrounding (still original) water tends to fill the gap. However, because of the Coriolis effect and as for a meteorological low-pressure system, this original water flows counterclockwise around the gap for some time (at least one year according to [38]). Now, because of the asymmetry induced by winds blowing from the coast, the surrounding flow of original (less dense) water is always narrower, more intense and hence deeper in the coastal zone, "just north" of the zone of dense water formation. This latter zone being always less stratified will be, in our theoretical case, a preferential zone for dense water formation during the next winter ... and the following ones as well! Practically, original water can be considered as the water encountered before winter in most of the basin, i.e. as AW per se. Since actual AW is continuously stratified, stratification will be maintained in the northern currents, even where meteorological conditions are the most severe.

\subsubsection{Another way to consider the Mediterranean Sea}

Instead of separating the Mediterranean Sea into two basins usually thought as having more differences than similarities, let us consider the sea as a three-level association of machines that, although being different in size and efficiency, are fundamentally similar. The third level could be formed by both the Aegean and the Adriatic (AA), the second level by the Levantine, the Cretan and the Ionian, i.e. the remainder of the eastern basin (EB), the first level by the whole western basin (WB). Each machine: 
- receives AW from the preceding level: from $\mathrm{EB}$ for $\mathrm{AA}$, from $\mathrm{WB}$ for $\mathrm{EB}$, from the Atlantic Ocean for WB,

- is characterised by an overall propagation of AW as an alongslope counterclockwise gyre,

- is such that the AW gyre is markedly unstable in the south with mesoscale anticyclonic eddies propagating downstream (eastwards): off Crete only (nothing adequate for the Adriatic) for AA, off eastern Libya and western Egypt for EB, off Algeria for $\mathrm{WB}$,

- receives intermediate and/or dense waters from outside: LIW for AA, AeDW and AdDW for EB, the outflow from the Channel of Sicily for WB,

- forms its own dense water according to offshore processes: AeDW and AdDW for AA, LIW for EB, WMDW for WB,

- forms less dense waters over continental shelves: in the northern parts of AA, in the Gulf of Lions for WB (nothing adequate for EB, not considering the shelf off southern Tunisia),

- is such that AW surrounds the offshore zone of dense water formation just north of it: in the north of the Southern-Aegean and of the Southern-Adriatic for AA, in the north of the Levantine for EB, in the north of the Ligurian and the Provençal for $\mathrm{WB}$,

- has topography (a more or less large trough or pit) so that densest waters must flow over a sill before cascading at lower levels: the Cretan and Otranto sills for AA, the Sicily sill for EB, the Gibraltar sill (probably after the Sardinia sill) for WB.

This analysis of the functioning of the sea could be used for analytical computations or simple numerical simulations.

\subsubsection{Circulation in the Black Sea}

To illustrate the fact indicated in the introduction that different forcings induce a roughly similar alongslope counterclockwise circulation, let us consider the case of the Black Sea. There, precipitation and river runoff exceed evaporation so that surface water outflows through the Bosphorus and the Dardanelles while deep waters are schematically at rest, not considering the slight inflow of MW from the Northern Aegean (e.g. [39]). It is now clearly demonstrated, from both remotely sensed (see Fig. 1) and in 
situ data sets, that fresh waters mainly issued from the surrounding terrestrial areas circulate all around the sea and form an unstable current that generates mainly mesoscale anticyclonic eddies (e.g. [40]).

\subsubsection{Other types of currents}

In addition to the currents associated with the circulation features described in this paper, be they associated with the major/named currents, gyres, veins, branches or mesoscale eddies, other types of currents must be considered, in particular for environmental purposes. First, oscillatory currents do not entrain any significant circulation of water particles and dissolved compounds, but significantly contribute to mixing and, in any case, complicate the in situ observation. Well-known tidal currents must be considered in most of the major passages (e.g. the Strait of Gibraltar, the Channel of Sicily), in some minor ones (e.g. the Strait of Messina) as well as in all coastal ponds outlets where they can reach a few m/s. Except in some very specific zones where these tidal currents are associated with few-metre sea-level oscillations (e.g. the Northern-Adriatic) and/or several 10s-m internal waves (e.g. the Strait of Gibraltar), they can be neglected since they are a few mm/s only (but still measurable, [41]). This is not the case for the less-known inertial currents that oscillate at the Coriolis frequency ( $\sim 17 \mathrm{~h}$, resp. $\sim 24 \mathrm{~h}$, in the far north, resp. south, of the sea) and are mainly induced by gusts of wind under stratified conditions. Although inertial currents reach maxima of a few $10 \mathrm{~s} \mathrm{~cm} / \mathrm{s}$ only, they can be encountered more or less in all seasons, everywhere and at greatest depths, even in almost homogeneous waters [42]. In addition, they markedly vary in time and space, both on the horizontal and the vertical, and can be associated with several 10s-m internal waves. Finally, large (several 10s to $100 \mathrm{~s} \mathrm{~m}$ ) vertical oscillations with periods of a few hours can be encountered in the zones of dense water formation. Contrary to the dissolved compounds that strictly follow the water particles and are submitted to the phenomena described up to now, floating compounds (e.g. oil released by tankers) are more directly submitted to the wind drag effect. The induced drift, not mentioned up to now since not thought important from a circulation point of view, is generally estimated to be some percents of the wind speed, roughly downwind (slightly on the right). 


\subsection{Some implications for environmental chemistry}

At large scale, an object theoretically able to keep the density that AW has before sinking (and not beaching!) will follow the circulation schema described in fig. 2 and will never escape from the Mediterranean Sea. On the contrary, any dissolved compound will follow one or the other of the circulation schemas in fig. 2, 3 and 4, and will finally escape from the sea. In general, it can be considered that the lower the depth within MWs the lower the residence time. Just dividing the volume of the sea by the outflow gives an average residence time for a dissolved compound of 50-100 years. However, the actual residence time at any given level ranges from less than a few hours/days to more than several centuries!

Any compound introduced into the sea by rivers will be preferentially transported, without any wind or marine current, along the coast on the right hand side, as a direct consequence of the Coriolis effect on the river plume (as for other waters). This tendency will be increased by winds blowing shoreward and decreased by winds blowing seaward (not considering the Coriolis effect on the drift current that induces a small component on the right). The overall circulation of $\mathrm{AW}$ as a gyre generally increases this tendency, as long as indentations of the coastline (in fact of the upper continental slope) are sufficiently large (several $10 \mathrm{~s} \mathrm{~km}$, i.e. gulfs) for allowing the Coriolis effect to be efficient in maintaining the circulation along the topography. When indentations are small (few-km, i.e. bays), the Coriolis effect cannot maintain the overall circulation along the topography; most of the circulation bypasses the bay where only part of the circulation can loop (e.g. [43]).

However, this overall circulation is not directly sensed everywhere in the coastal zone (up to a few $\mathrm{km}$ wide). This is because a basin-wide gyre has a width (a few to several 10s km) and a thickness (a few 100s m) that make it following the largest topographic features only. Its core (maximum speeds of several $10 \mathrm{~cm} / \mathrm{s}$ ) is always located a few $10 \mathrm{~s} \mathrm{~km}$ seawards at least, and it can influence the circulation in the coastal zone through its inner (i.e. right-hand) edge only (e.g. [17]). Natural turbulence on the edges of any major current and interaction of the current itself with smaller topographic features will make the circulation in the coastal zone relatively complex. In this respect, 
the turbulent character of the actual alongslope currents, i.e. the turbulent diffusion they induce, facilitates the seaward spreading of compounds originated in the coastal zone. Therefore, the gyre of AW does not act as a barrier for on-offshore exchanges (which would be the case for laminar currents).

Once coastal compounds have entered the gyre (of AW or MWs, i.e. whatever the depth), they can be entrained either mainly alongslope (over 100s km) if in the northern part of the basin (where currents are relatively stable) or in any direction if in the southern one. More specifically, a compound released from Algeria for instance is entrained, most of the time and hence on average, eastwards. However, an anticyclonic eddy located just offshore can entrain it westwards. It can also be entrained directly northwards, when a large eddy located just downstream strongly interacts with the Algerian Current itself and makes it leaving the coast at right angle [14]. Finally, it can be constrained along the coast when an anticyclonic eddy is located just upstream and induces a current impinging the coast southwards (this situation is temporary since the compound will sooner or later be entrained either westwards or eastwards).

Direct links are often made between Saharan dusts transported over the sea by southerly winds, as seen on visible satellite images, and their input into the sea itself. However, it might not be trivial to note that compounds originated from atmospheric sources have to enter the sea! Indeed, dust are seen from space mainly in the absence of clouds, and hence precipitations; therefore, only a part of that dust will directly reach the sea, the remainder falling elsewhere, i.e. on land, before being transported later on into the sea by rivers. It might be (we believe!) that most of the Saharan dust is transported directly into the sea by rainy, hence cloudy meteorological events during which dust cannot be seen. Note that the circulation modifies a spatially homogeneous sowing of dust just slightly (due to stratification and vertical currents), while it distorts a patchy sowing (due to the heterogeneity of the current field).

When dealing with suspended particles, or chemical compounds associated in aggregates, one must keep in mind the dramatic difference between the intensity of the horizontal currents (a few to several tens of $\mathrm{cm} / \mathrm{s}$ ) within gyres and mesoscale eddies, and that of mean falling speeds (of the order of the mm/s). Any suspended particle 
found alongslope (where more or less permanent circulation occurs) could thus have been introduced at the surface of the sea $10 \mathrm{~s}$ or $100 \mathrm{~s} \mathrm{~km}$ upstream. In the central part of the basins, the origin is generally even more uncertain.

\section{Conclusion}

Climatic conditions are such that the two basins of the semi-enclosed Mediterranean Sea are characterised by an excess of evaporation over precipitation and river runoff. Just because the level of the sea is thus decreased, water is coming in from the Atlantic to compensate for the deficit; the fact that AW is coming in at the surface only needs the comments hereafter to be understood. Due to these climatic conditions, the incoming surface water is essentially made saltier, hence denser, all along its course within the sea. In winter cool (and dry) air masses transported by northerly winds blowing strongly in a few specific zones make surface water denser and denser. This water is finally densified so much that it sinks in these specific zones. Because it has been continuously transformed, due to the climatic conditions and the mixing with surrounding waters, this surface water sinks with characteristics that depend on the zone and are relatively typical, leading to a set of more or less dense Mediterranean waters. These waters then circulate in the different subbasins, and mix more or less up to a certain amount before outflowing through the Strait of Gibraltar (mixing is completed during the outflow and consecutive sinking). Fundamentally, the sea is thus a machine that transforms Atlantic surface water encountered right west of Gibraltar into denser (essentially saltier and additionally colder) water that is recognised at 1000$2000 \mathrm{~m}$ in most of the northern Atlantic Ocean.

Apart from this well agreed functioning, the circulation of the various waters from/to the Strait of Gibraltar and the Channel of Sicily to/from the zones of sinking, is more and more agreed on in the western basin and starts to be debated (this will last for a while!) in the eastern basin. Since the differences between the circulation schemas published up to now have already been commented for both basins $[30,9,7]$, and since this introductory chapter must provide a coherent -although not fully agreed onanalysis, the presentation was restricted to the authors' analysis. 
Due to the Coriolis effect, which deflects to the right in the northern hemisphere any movement having relatively large space and time scales, all waters that are forced to circulate at basin scale (at all depths!) tend to follow, in the counterclockwise sense, the isobaths corresponding to their own level. Simply considering that waters hence form basin-wide gyres a few tens of km wide following mainly the continental slope at all depths provides a relatively simple overall circulation schema.

For the flow of surface water, this schema is complicated first at the entrance of the basins, mainly due to the complexity of the topography that extends its influence more or less far downstream (the Alboran and the Ionian, resp.). Then, the flow tends to structure itself as a basin-wide gyre (off western Algeria and off Cirenaïca, resp.). However, it is much less dense than the water below, hence markedly unstable, so that southern portions of the gyres have received specific names (the Algerian Current and the Libyo-Egyptian Current, resp.). These currents are unstable all year long and, a few times per year, they generate especially large (up to $250 \mathrm{~km}$ ) anticyclonic eddies that propagate downstream (at up to a few $\mathrm{km} /$ day) and can extend down to the bottom (2$3000 \mathrm{~m}$ ). Hence, these eddies follow the deeper isobaths, thus being led by topographic features (the Tunisian and Sardinian shelves, the Herodotus trough, resp.) to separate from their parent current. They can drift for years (up to 3 at least) in the central part of the basins, and be more or less trapped by the deep topography. Together with not so deep eddies that might be entrained southwestwards by the $\beta$-effect (variation of the Coriolis effect with the latitude) and non-linearities, they possibly interact with their parent current. Other large mesoscale eddies are induced by some wind regimes, especially in the eastern basin. Together they tend to export AW seawards and they entrain both intermediate and deeper waters away from the continental slopes. Hence, the middle and southern parts of both basins (off Algeria, off eastern Libya and western Egypt, resp.) display similar characteristics resulting from similar processes.

Downstream from these specific zones characterised by intense mesoscale variability, the flow of surface water restructures itself as a basin-wide gyre. In the southeastern, eastern and northeastern parts of the basins, both gyres are characterized by a mesoscale activity that is reduced in the western basin and still significant, although 


\section{Circulation in the Mediterranean}

of smaller scale, in the eastern basin. In the northern part of both basins (and in the southern part of the Aegean and in the Adriatic), the gyres are closely linked to the offshore zones of dense water formation that they partly surround. Although the term of Northern Current was proposed for both basins [1], it is more easily identified in the western basin (from southern Italy to France and southern Spain) than in the eastern basin (due to a more complex topography and a seasonality of the wind regime more marked there). However, the portion of the eastern gyre formerly named Asia Minor Current can be considered as the counterpart of the Northern Current for the western gyre, although more unstable (up to generating medium scale eddies). In any case, the northern parts of both basins display (we believe!) similar characteristics resulting from similar processes too.

Therefore, and although the actual circulation in the whole Mediterranean Sea is relatively complex, it can be thought as mainly resulting from a fundamental driving mechanism, the water deficit, and two major phenomena, the Coriolis effect and the mesoscale variability (be it induced by the instability of alongslope currents or by the wind). Whatever the validity of our analysis about the similarities and differences between the different parts of the sea, the circulation schemas we propose are consistent with i) our original hypotheses [1, 2], ii) all available data sets and iii) the most recent numerical simulations.

\section{Acknowledgements.}

This overall analysis is based on a series of works done in collaboration with many colleagues that are all warmly thanked and intimately associated. We would also like to thank all the crews and organisms that have made possible the collection of what starts to be a significant amount of data sets, collected either in situ (mainly thanks to the CNRS, the "Centre National de la recherche Scientifique", and IFREMER, the "Institut Français pour la Recherche et l'Exploitation de la Mer") remotely sensed (mainly thanks to the SATMOS/CMS, the "Centre de Météorologie Spatiale" of Météo-France, and the DLR, the "Deutsches Zentrum für Luft- und Raumfahrt"). 


\section{$\underline{\text { References }}$}

1. Millot C., 1992. Are there major differences between the largest Mediterranean seas? A preliminary investigation. Bulletin de l'Institut Océanographique, Monaco, 11, 3-25.

2. Le Vourch J., C. Millot, N. Castagné, P. Le Borgne and J.P. Olry, 1992. Atlas of Thermal Fronts of the Mediterranean Sea Derived From Satellite Imagery. Mémoires de l'Institut Océanographique, Monaco, 16, 146p.

3. Millot C. and I. Taupier-Letage, 2004. Additional evidence of LIW entrainment across the Algerian Basin by mesoscale eddies and not by a permanent westward-flowing vein. Prog. Oceanogr., in press

4. Robinson, A.R., and M. Golnaraghi, 1993. Circulation and dynamics of the Eastern Mediterranean Sea; quasi-synoptic data-driven simulations. Deep Sea Res., 40 (6), 1207-1246.

5. Malanotte-Rizzoli, P., Manca, B.B., Ribera d'Alcala, M., Theocharis, A., Bergamasco, A., Bregant, D., Budillon, G., Civitarese, G., Georgopoulos, D., Michelato, A., Sansone, E., Scarazzato, P., and Souvermezoglou, E., 1997. A synthesis of the Ionian Sea hydrography, circulation and water mass pathways during POEMPhase I. Prog. Oceanogr., 39, 153 -204.

6. Nielsen, J.N., 1912. Hydrography of the Mediterranean and adjacent waters. Rep. Dan. Oceanogr. Exp. Medit., 1, 77-192.

7. Hamad N., C. Millot and I. Taupier-Letage, 2004. The surface circulation in the eastern basin of the Mediterranean Sea as inferred from infrared images. Prog. Oceanogr., in press.

8. Alhammoud B., K. Béranger, L. Mortier, M. Crépon, an I. Dekeyser, 2004. Surface circulation of the Levantine Basin: comparison of model results with observations, Prog. Oceanogr., in press.

9. Millot C., 1999. Circulation in the Western Mediterranean sea. J. Mar. Sys., 20, 1-4, 423-442.

10. Millot C., 1985. Some features of the Algerian Current. J. Geophys. Res., 90, C4, 7169-7176.

11. Puillat I., I. Taupier-Letage and C. Millot. Algerian eddies lifetimes can near 3 years, 2002. J. Mar. Sys., 31, 4, 245-259. 
12. Fuda J.-L., C. Millot, I. Taupier-Letage, U. Send and J.M. Bocognano, 2000. XBT monitoring of a meridian section across the Western Mediterranean Sea. DeepSea Res., I 47, 2191-2218.

13. Ruiz S., J. Font, M.Emelianov, J. Isern-Fontanet, C. Millot and I. Taupier-Letage, 2002. Deep structure of an open sea eddy in the Algerian Basin. J. Mar. Sys., 33$34,179-195$.

14. Taupier-Letage I. and C. Millot, 1988. Surface circulation in the Algerian Basin during 1984. Oceanol. Acta, sp. $n^{\circ}$ 9, 119-131.

15. Millot C., 1991. Mesoscale and seasonal variabilities of the circulation in the western Mediterranean. Dyn. Atm. Oceans, 15, 179-214.

16. Béranger K., L. Mortier and M. Crépon, 2004. Seasonal variability of transports through the Gibraltar, Sicily and Corsica straits from a high resolution Mediterranean model, Prog. Oceanogr., in press.

17. Albérola C., C. Millot and J. Font, 1995. On the seasonal and mesoscale variabilities of the Northern Current during the PRIMO-0 experiment in the western Mediterranean Sea. Oceanol. Acta, 18, 2, 163-192.

18. Wald L., 1985. Apport de la télédétection spatiale en infrarouge proche et moyen à la connaissance du milieu marin: relations entre le champ de températures et le champ de courant, observations de l'état de surface et mesures de la vitesse du vent, la dynamique de la couche superficielle en Mer Ligure. Thèse de Doctorat d'Etat, Université de Toulon et du Var, France.

19. Taupier-Letage I. and C. Millot, 1986. General hydrodynamical features in the Ligurian Sea inferred from the DYOME experiment. Oceanol. Acta, 9, 2, 119-131.

20. Schott F. and K. Leaman, 1991. Observations with moored acoustic Doppler current profilers in the convection regime in the Golfe du Lion. J. Phys. Oceanogr., $21,558-574$.

21. Millot C. and A. Monaco, 1984. Deep intense currents and sedimentary transport in the northwestern Mediterranean Sea. Geo-Marine Letters, 4, 1, 13-17.

22. Millot C., 1990. The Gulf of Lions' hydrodynamics. Continental Shelf Res., 10, 9-11, 885-894.

23. Millot C., 1979. Wind induced upwellings in the Gulf of Lions. Oceanol. Acta, 2, 3, 261-274. 
24. Lopez-Garcia M. J., C. Millot, J. Font and E. Garcia-Ladona, 1994. Surface circulation variability in the Balearic Basin. J. Geophys. Res., 99, C2, 3285-3296.

25. Fuda J.-L. , G. Etiope, C. Millot, P. Favali, M. Calcara, G. Smriglio and E. Boschi, 2002. Warming, salting and origin of the Tyrrhenian Deep Water. Geophys. Res. Letters, 29(18), 1886, doi:10.1029/2001GL014072, 2002.

26. Salas J., C. Millot, J. Font and E. García-Ladona, 2002. Analysis of mesoscale phenomena in the Algerian Basin observed with drifting buoys and infrared images. Deep-Sea Res., 49, 2, 245-266.

27. Lermusiaux P. F. J. and A. R. Robinson, 2001. Features of dominant mesoscale variability, circulation patterns and dynamics in the Strait of Sicily. Deep Sea Res., $48,9,1953-1997$

28. Pierini, S., and A. Rubino, 2001. Modelling the oceanic circulation in the area of the strait of Sicily: the remotely forced dynamics. J. Phys. Oceanogr., 31 (6), $1397-$ 1412.

29. Ovchinnikov I., Y. Popov and I. Gertman, 1990. Investigation of the formation of deep waters in the eastern Mediterranean sea during the $36^{\text {th }}$ cruise of the $\mathrm{R} / \mathrm{V}$ Ya. Oceanology, 30, 6, 769-771

30. Millot C., 1987. Circulation in the Western Mediterranean. Oceanol. Acta, 10, 2, 143-149.

31. Astraldi M., G.-P. Gasparini, L. Gervasio and E. Salusti, 2001. Dense water dynamics along the Strait of Sicily (Mediterranean Sea). J. Phys. Oceanogr., 31, 12, 3457-3475.

32. Klein B., W. Roether, B. Manca, D. Bregant, V. Beitzel, V. Kovacevic and A. Lucchetta, 1999. The large deep water transient in the Eastern Mediterranean. Deep-Sea Res., 46, 371-414.

33. Lacombe H., P. Tchernia and L. Gamberoni, 1985. Variable bottom water in the Western Mediterranean basin. Prog. Oceanogr. 14, 319-338.

34. Sparnocchia, S., G. P. Gasparini, M. Astraldi, M. Borghini, and P. Pistek, 1999. Dynamics and mixing of the Eastern Mediterranean outflow in the Tyrrhenian Basin, J. Mar. Syst., 20, 301-317.

35. Kinder, T., Parrilla, G., 1987. Yes, some of the Mediterranean outflow does come from great depths. J. Geophys. Res. 92, 2901-2906. 
36. Testor P. and J.-C. Gascard, 2004. Large scale flow separation and mesoscale eddy formation in the Algerian Basin, Prog. Oceanogr., in press.

37. Millot C., I. Taupier-Letage and M. Benzohra, 1997. Circulation off Algeria inferred from the Médiprod-5 current meters. Deep-Sea Res., 44, 9-10, 1467-1495.

38. Crépon, M., Boukthir, M., Barnier, B., Aikman III, F., 1989. Horizontal ocean circulation forced by deep water formation: Part I. An analytical study. J. Phys. Oceanogr. 19, 1781-1792.

39. Ozsoy E., D. Rank and I. Salihoglu, 2002. Pycnocline and deep mixing in the Black Sea: stable isotope and transient tracer measurements. Estuarine, Coastal and Shelf Sci., 54, 3, 621-629.

40. Ginzburg A., A. Kostianoy, N. Nezlin, D. Soloviev and S. Stanichny, 2002. Anticyclonic eddies in the northwestern Black Sea. J. Mar. Sys., 32, 91-106.

41. Albérola, C., Rousseau, S., Millot, C., Astraldi, M., Garcia-Lafuente, J.J., Gasparini, G.P., Send, U., Vangriesheim, A.,1995. Tidal currents in the Western Mediterranean Sea. Oceanol. Acta 182 , 273-284.

42. van Haren H. and C. Millot, 2004. Rectilinear and circular inertial motions in the Western Mediterranean Sea. Oceanol. Acta, in press.

43. Albérola C. and C. Millot, 2003. Circulation in the French Mediterranean coastal zone near Marseilles : the influence of the wind and the Northern Current. Cont. Shelf Res., 23, 6, 587-610. 